\title{
Strategic Trade Policy and Mode of Competition: Symmetric versus Asymmetric Information
}

\author{
Delia Ionaşcu and Krešimir Žigić \\ CERGE-EI, Prague* \\ CERGE-EI \\ Politickych veznu 7 \\ 11121 Prague 1 \\ Czech Republic
}

\begin{abstract}
In this paper, we analyze the following policy dilemma: strategic trade policy versus free trade when the domestic government is bound to intervene only after the domestic firm's strategic variable is chosen. This intervention allows the domestic firm to manipulate the domestic government and results in a socially inefficient choice of the strategic variable. However, commitment to free trade leads to forgoing the benefits from profit-shifting. Yet, from the social point of view, free trade may be optimal even under the assumption of symmetric information. Due to costly signaling, this result is reinforced in the case of asymmetric information.
\end{abstract}

\begin{abstract}
Abstrakt
Článek analyzuje dilema strategická obchodní politika versus volný obchod v př́ípadě, kdy domácí vláda může intervenovat na trhu až poté, co domácí firma provede volbu strategické veličiny. V takovém případě může domácí firma manipulovat domácí vládou, což vede k sociálně neefektivní volbě strategické veličiny. Závazek domácí vlády k politice volného obchodu zase připraví domácí firmu o zisk z tranferu profitu (od zahraniční k domácí firmě), který by se realizoval v př́padě jiné obcbodní politiky. Přesto může být ze společenského hlediska politika volného obchodu optimální, a to dokonce i za předpokladu symetrické informovanosti. V prŕpadě nesymetrické informovanosti platí stejný výsledek tím spíše, že signalizace je nákladná.
\end{abstract}

Keywords: strategic trade policy, free trade, first-best versus second best policy, government's commitment, signaling

\section{JEL: F13}

\footnotetext{
* Center for Economic Research and Graduate Education - Economics Institute, Prague
} 


\section{INTRODUCTION}

Despite convincing theoretical arguments that favor strategic trade policy over free trade in imperfectly competitive markets, the practical application of strategic trade seems to be plagued by both operational and political economy considerations. Operationally, the optimal intervention depends critically on details concerning market structure and market conduct that enforce a demanding information requirement on policy makers. The most striking example (and probably the most cited reference) in this respect, is that of Eaton and Grossman (1986) which showed that levying a tax on a domestic firm's output is an optimal policy if domestic and foreign firms compete in prices on the third market, whereas subsidizing a domestic firm's output is the proper thing to do if firms compete in quantities in the same setup. The well-known political economy concerns about the use of strategic trade are the likely applying of political pressure, lobbying, or rent seeking.

It is, however, important to note that the likely lack of key information and the rent-seeking “...would speak against all forms of government intervention, inasmuch as policy makers rarely have all the information they need to implement the policies prescribed by economic theory" (Grossman and Maggi, 1998) and inasmuch as they are exposed to interest groups pressure. Thus, these two points ${ }^{1}$ are always put forward by the advocates of free trade whenever there is a discussion about the potential practical net benefits of strategic trade policy (see, for instance, Bhagwati, 1989, or Krugman, 1987).

The motivation of this paper is to provide an explicit model that takes into account some of the problems that constrain the application of unilateral strategic trade policy. It seems that Eaton and Grossman's (1986) critique set the course for subsequent research in this field. They emphasized the importance of the mode of market competition in the design of the optimal strategic trade policy. In this light, their criticism calls for an approach that looks for more robust policy instruments than the standard tools, such as export subsidies or taxes. Thus, Maggi (1996) shows that capacity subsidy is generally a welfare improving policy regardless of the mode of competition, and Bagwell and Staiger (1994) indicates that R\&D subsidies might also be the best policy in both Cournot and Bertrand setups. ${ }^{2}$ Žigić (1998), on the other hand, studied the possibility of the government to infer the relevant information about the market conduct from a given market setup while keeping standard (sensitive to the type of competition) instruments like a specific tariff. He has shown that policy makers can, in specific situations, correctly infer the underlying type of

\footnotetext{
${ }^{1}$ In fact, there is also a third argument not dealt with in our paper that also constrains the use of strategic trade policy, namely, that strategic trade policy enacted in one country (that can in principle be welfare enhancing) may spur the usage of trade policies in the affected countries making everybody worse off ultimately.
} 
market competition from certain observable data and set the selected policy instrument at its optimal level.

Grossman and Maggi (1998), have initiated a somewhat different strand of research. They explicitly analyzed the impact of uncertainty on the key policy dilemma - free trade versus strategic trade policy - in a plausible setup in which the domestic firm displays a manipulative behavior against its government. The uncertainty, in their model, comes from the unknown cost efficiency of the domestic firm while the manipulative behavior stems from the possibility of the domestic firm to extract a high export subsidy from the government by overinvesting in R\&D. More precisely, the government may or may not be completely informed about the cost efficiency of its own firm. When the government has full information, the distortion of social welfare arises from the manipulating behavior of the domestic firm. This behavior has its grounds in an assumption that between the announcement of intervention and the actual setting of the trade policy, the firm can take some strategic action (investment in R\&D in this case) that will influence the optimal level of subsidy. This assumption, (crucial to both Grossman and Maggi (1998) and our approach), implies that for some reason the government is unable to commit inter-temporally and enacts an export subsidy only after the firm sets the R\&D level. ${ }^{3}$ The more efficient the firm, the more it invests and exports and the more subsidy payment it gets. In the case of asymmetric information a high efficiency firm might use its investment level to signal its efficiency type and thus, gain a higher subsidy. Hence, there will be an additional manipulative factor that will distort even further the social welfare.

Our approach aims to merge the Grossman and Maggi (1998) model of the impact of uncertainty on the desirability of strategic trade vis-a-vis free trade and the Eaton and Grossman (1986) finding regarding the importance of the mode of competition for the design of the optimal strategic trade policy. More specifically, we assume that the uncertainty for the domestic government stems from the unknown mode of competition. As Grossman and Maggi themselves admitted, this type of uncertainty "... might appear more crucial than our cost parameter." Much like Grossman and Maggi (1998), we consider a so-called third market model (see Brander, 1995 for a survey of this class of models) in which domestic and foreign firms compete in a third country's market but the exportable good is not used by domestic consumers. ${ }^{4}$ We examine a (potentially) four-stage dynamic game. In the first stage the domestic government decides whether or not to

\footnotetext{
${ }^{2}$ However, Neary and Leahy (2000) pointed out that R\&D subsidies are only a second-best choice. A first best policy would be a combination of R\&D tax (subsidy) with export subsidy (tax).

${ }^{3}$ For a rationale of such timing, see Karp and Perloff (1995) who first introduced this setup. For somewhat different but related reversals of moves between government and the firm and the justification for it, see Gruenspecht (1988). See also Carmichael (1987) and Neary (1994).

${ }^{4}$ This oversimplification is made with the purpose of focusing exclusively on the strategic aspects of trade policy. As Helpman and Krugman (1989) pointed out, a model that neglects the consumer surplus "...may be useful in isolating some interesting effects .." (Helpman and Krugman (1989), p 84)
} 
commit to free trade. Given that, in the second stage, the domestic firm chooses how much to invest in process innovation ( $R \& D$ investment) that leads to marginal cost reductions. However, the chosen level of the marginal cost reduction crucially depends on whether the government has committed to free trade or not. If the government did not make a commitment to free trade, it would find it optimal to intervene ex post by adopting the output subsidy rule in the third stage. The rational firm would anticipate this when choosing its level of R\&D investment. An alternative justification for such ex post intervention, as already mentioned, is when the government is unable to commit to its policy instrument prior to the domestic firm's strategic choice due to the lag between the policy announcement and its implementation. Finally, in the fourth stage, the firms compete in either price or quantity. The government can be either perfectly or imperfectly informed about the mode of competition (which can be either of the Bertrand or the Cournot type).

As is already clear, the basic difference from Grossman and Maggi (1998) is in the type of uncertainty $^{5}$. In the Grossman and Maggi's (1998) model the government is not informed of the cost efficiency of its own firm, while in our scenario the domestic government does not know the type of market competition. As before, between the government's announcement of intervention and its choice of the output subsidy, the domestic firm will make its R\&D investment decision. The result of the investment will be a decrease in its marginal cost. In the case of asymmetric information, the investment decision (more precisely the level of the unit cost reduction, $x$ ) will be used by the government to infer the market structure since firms competing à la Bertrand underinvest in R\&D, while firms competing à la Cournot overinvest. The notion of "underinvestment" or "overinvestment" is used vis-à-vis the non-strategic benchmark in which the domestic firm does not take into account the impact of its R\&D investment on the subsequent choice of either quantity or price by the foreign firm (see Spencer and Brander, 1983 and Tirole, 1988). However, since the domestic firm knows that the government makes its decision based on the observed investment level, it will try to influence the government's decision through a specifically chosen level of R\&D.

The other key difference with Grossman and Maggi (1998) is that we use a model with differentiated products while Grossman and Maggi (1998) use an assumption of homogeneous good and as a result we are able to study the impact of product differentiation on the optimal choice between strategic trade and free trade.

Thus, apart from these two critical differences (the type of uncertainty and differentiated versus homogenous products), the structure and the timing of Grossman and Maggi (1998) and our

\footnotetext{
${ }^{5}$ For a somewhat different modelling of the strategic trade policy under asymmetric information see for instance, Qiu (1994) and Maggi (1999).
} 
model is basically the same. The adopted setup looks rather simple yet it contains (albeit more implicitly) all three relevant strategic considerations faced by the domestic government conducting unilateral strategic trade policy. ${ }^{6}$ The first is the standard "profit shifting" motive, the second deals with the government's attempt to counteract the domestic firm's strategic over or underinvestment and, the third is directed towards counteracting the domestic firm's manipulatory behavior (see Leahy and Neary, 2000). Thus, in our context (in which the government cannot commit intertemporally), the first best policy under perfect information would be for the government to tax (subsidize) R\&D in the second stage of the game in order to correct for the second and third strategic motive and then subsidize (tax) output at a later stage of the game in order to induce profit shifting towards the domestic firm (see Spencer and Brander, 1983 and Leahy and Neary, 2000). However, under our assumptions, the government can use only output subsidies and thus, is unable to directly counteract the over (under) investment and the manipulatory behavior of the domestic firm. This setup seems more realistic than the "first best" policy especially when we extend our analysis to the incomplete information case where committing to any policy before observing the R\&D signal may be harmful. ${ }^{7}$ However, we do compare the first-best values of the unit cost reduction with their actual "second-best" counterparts and we contrast the resulting welfare differences between the first-best and the second-best policy options.

Our analysis reveals a number of interesting findings. First, the standard results in which the Bertrand firm underinvests while the Cournot firm overinvests in marginal cost reduction is reinforced in the applied setup due to the manipulating behavior of the domestic firm. Secondly, the Grossman and Maggi (1998) result obtained under the assumption of Cournot competition and the homogenous products in which government intervention is optimal for high unit R\&D investment costs, carries over to our setup with product differentiation and is valid for both Cournot and Bertrand type of competition. In other words, a perfectly informed government will enact a trade policy (regardless of the type of competition in the market) when the cost parameter of $R \& D$ investment, labeled $k$, is high enough, while free trade will be optimal when investment costs are low. However, the degree of product differentiated affects the critical level of $k$, above which the strategic trade policy is optimal. When products get less differentiated, larger value of investment cost tilt the balance towards free trade since on the margin the increase in profit induced either by higher subsidy (Cournot case) or by lower tax bill (Bertrand case) becomes more important than the profit from output revenue. In other words, as products become more homogenous, there is an increase in manipulatory actions on domestic government, and therefore a welfare maximizing

\footnotetext{
${ }^{6}$ In fact, there is also a fourth strategic motive when there is strategic response by foreign governments. As was already indicated, this case is not considered in our paper.

${ }^{7}$ The other reasons might be that a government has a constrain budget to conduct the first best policy when R\&D subsidies are optimal (see Leahy and Neary, 2000, for more about both "first " and the "second best policy")
} 
government will enact more often free trade.

Thirdly, under the perfect information setup, the welfare losses from using the "second best" policy versus the first best policy described above are generally small.

Finally, with asymmetric information, there may be an additional manipulating effect in the case when the government does not commit to free trade and competition is à la Cournot. This manipulating effect, manifested through costly signaling, leads to even larger overinvestment than in the case under the perfect information and therefore the social welfare in this case is always lower than in the corresponding free trade regime. Thus, the government prefers to opt for free trade in general unless the probability of the Bertrand competition is "high" and the unit cost of R\&D investment are "large enough" to justify intervention. Thus, free trade has a special role in the given setup: it serves as a device that protects the government from the socially costly manipulation of domestic firms.

The paper is organized in the following way. The next section deals with the case of perfect information and identifies the optimal output policy for each of the two types of competition. Section 3 briefly compares the second best policy with its first best counterpart. Section 4 analyses the game in an asymmetric information context in which the domestic government is not fully informed about the type of market interaction. The last section discusses the findings of this paper.

\section{The Model - The Full Information CaSe}

Consider a differentiated product market in which there are only 2 firms - firm F1, the domestic firm, and firm F2, the foreign firm - competing à la Bertrand or à la Cournot in a third market. In order to get the explicit solution of the model we use a version of the linear inverse demand for firms' products of the following type:

$$
p^{i}\left(q^{i}, q^{j}\right)=1-\beta\left(q^{i}+\gamma q^{j}\right)
$$

whereas the corresponding direct demands are ${ }^{8}$

$$
q^{i}\left(p^{i}, p^{j}\right)=\frac{1}{\beta(1+\gamma)}\left(1-\frac{1}{1-\gamma} p^{i}+\frac{\gamma}{1-\gamma} p^{j}\right)
$$

$\beta>0$ and concavity of the underlying utility function requires $0<\gamma<1$. The parameter $\gamma$ is the product differentiation parameter; when products get more alike $\gamma$ tends to unit while when products are not related $\gamma$ goes to zero.

\footnotetext{
${ }^{8}$ See Martin (1993) for more about the properties of this (inverse) demand system.
} 
Both firms have initially the same efficiency translated into the same constant marginal cost $c\left(0<c<1^{9}\right)$. However, through research and development (R\&D) activity firm F1 is able to decrease its production cost. In order to get $x$ decrease in its marginal cost, firm F1 has to invest $k x^{2}$. The parameter $k$ measures the efficiency of $\mathrm{R} \& \mathrm{D}$ investment: the higher $k$ is, the lower the $\mathrm{R} \& \mathrm{D}$ efficiency (or equivalently, the more expensive R\&D investments are). The latter specification is standard in the strategic R\&D literature (see for instance, D'Aspremont and A. Jacquemin, 1988, Hinloopen, 1997, Leahy and Neary, 1997, Grossman and Maggi, 1998, etc).

For the moment we assume that the type of competition in the market is known by the firms as well as by the governments. For the reasons explained in the introduction, but also to preserve the setup comparable with Eaton and Grossman (1986) and especially with Grossman and Maggi (1998), we assume that the domestic government is considering interfering in the market only through an export (output) subsidy. As we said earlier, the timing of the game is the following: the domestic government decides whether to commit to free trade or not. Following the government's decision, firm F1 invests in R\&D. If there was no commitment to free trade, the government sets the level of the output subsidy $s$ (or tax if this subsidy is negative) according to the observed investment level (or equivalently, according to the observed type of competition). If the government commits itself to free trade at the first stage, the level of subsidy/tax will be zero. In the end, production and competition in the market will take place. In what follows, we will consider this setup of the model for each type of competition separately.

We will not discuss corner solutions. We will consider only ranges of parameters for which all the sufficient second order conditions hold, and all solutions are interior solutions (more precisely, we will consider the conditions under which both firms are in the market in the Nash equilibrium, and the optimal level of increase in efficiency is smaller than $c$.) ${ }^{10}$ Therefore, in what follows we will consider that

$$
\begin{aligned}
& \frac{2-\gamma}{2 k \beta\left(2-\gamma^{2}\right)^{2}-\gamma}<c<1-\frac{\gamma}{2-\gamma^{2}}, \text { and } \\
& k>\frac{4-3 \gamma^{2}}{\beta 2(1-\gamma)(2+\gamma)\left(2-\gamma^{2}\right)^{2}}=\underline{k} .
\end{aligned}
$$

\subsection{Cournot Competition}

Considering the above specifications, the profits $\pi^{1}$ and $\pi^{2}$ of firm F1 and firm F2

\footnotetext{
9 The condition $0<\mathrm{c}<1$ ensures that the market exists, namely that the monopolist profit (for $\gamma=0$ ) is positive.

${ }^{10}$ For several reasons, we do not think that by ignoring the corner solutions we lose any interesting results. First, we would like to characterize markets in which there are at least two competitors. Second, in real life nothing can be produced with 0 marginal cost (regardless of the amount of effort oriented to innovation).
} 
respectively are given by

$$
\begin{aligned}
& \pi^{1}\left(q^{1}, q^{2} ; x, s\right)=q^{1}\left[p^{1}\left(q^{1}, q^{2}\right)-(c-x-s)\right]-k x^{2} \\
& \pi^{2}\left(q^{1}, q^{2} ; x\right)=q^{2}\left[p^{2}\left(q^{1}, q^{2}\right)-c\right]
\end{aligned}
$$

where the inverse demands are given by (i) and where the level of subsidy $s$ is zero in the case of free trade (no government intervention).

Firms choose their equilibrium quantities according to the first order conditions

$$
\begin{aligned}
& 1-(c-x-s)-2 \beta q^{1}-\beta \gamma q^{2}=0 \\
& 1-c-2 \beta q^{2}-\beta \gamma q^{1}=0 .
\end{aligned}
$$

Following the first order conditions (1) and (1'), the demands are given by:

$$
\begin{aligned}
& q^{1}(x, s)=\frac{1}{\beta\left(4-\gamma^{2}\right)}[(2-\gamma)(1-c)+2(x+s)] \\
& q^{2}(x, s)=\frac{1}{\beta\left(4-\gamma^{2}\right)}[(2-\gamma)(1-c)-\gamma(x+s)]
\end{aligned}
$$

and the inverse demands by:

$$
\begin{aligned}
& p^{1}(x, s)=\frac{1}{4-\gamma^{2}}\left[(2-\gamma)+\left(2+\gamma-\gamma^{2}\right) c-\left(2-\gamma^{2}\right)(x+s)\right] \\
& p^{2}(x, s)=\frac{1}{4-\gamma^{2}}\left[(2-\gamma)+\left(2+\gamma-\gamma^{2}\right) c-\gamma(x+s)\right] .
\end{aligned}
$$

The impact of R\&D and the subsidy on quantities differs from one firm to the other. As is well known, this impact is positive for the domestic firm and it is negative for the foreign firm.

\subsubsection{Free Trade}

If the government announced free trade during the first stage of the game, firm F1 chooses a level of increase in efficiency $x$ that maximizes the following profit function

$$
\pi^{1}(x, 0)=\frac{1}{\beta\left(4-\gamma^{2}\right)^{2}}[(2-\gamma)(1-c)+2 x]^{2}-k x^{2} .
$$

As a result, the domestic firm will choose a level of decrease in unit cost

$$
x_{f t}^{C}=\left\{\begin{array}{rr}
\frac{2(2-\gamma)}{k \beta\left(4-\gamma^{2}\right)^{2}-4}(1-c) & \text { if } c>\frac{2(2-\gamma)}{k \beta\left(4-\gamma^{2}\right)^{2}-2 \gamma} \\
c & \text { otherwise }
\end{array} .\right.
$$

Consequently, the domestic firm's profit and welfare will be equal to 


$$
\pi_{f t}^{C}=W_{f t}^{C}=\frac{k(2-\gamma)^{2}}{k \beta\left(4-\gamma^{2}\right)^{2}-4}(1-c)^{2}
$$

\subsubsection{Strategic Trade}

Without commitment to free trade, a subsidy program will be implemented. The government's objective function will turn to $\mathrm{be}^{11}$

$$
W(s)=\pi^{1}(x, s)-s q^{1}(x, s) .
$$

This objective function can be rewritten as

$$
W(s)=q^{1}(x, s)\left[p^{1}(x, s)-(c-x)\right]-k x^{2} .
$$

Thus, domestic welfare coincides with F1's net-of-subsidy profit. The first order condition implies ${ }^{12}$

$$
\frac{d W}{d s}=0 \Rightarrow \frac{\partial q^{1}}{\partial s}(x, s)\left[p^{1}(x, s)-c+x\right]=-q^{1}(x, s) \frac{\partial p^{1}}{\partial s}(x, s) .
$$

Thus, the marginal social benefit of the incremental increase in subsidy (expressed here as the marginal profit of a domestic firm) has to be equal in equilibrium to the marginal social costs (whereby these costs stem from the decrease in domestic firm profit due to the adverse affect of the subsidy on the equilibrium price). The optimal subsidy has to balance these two opposite effects. More generally, the rationale for a policy intervention in this setup is that in a pure Nash equilibrium, the domestic firm while choosing its quantity does not take into account its impact on the quantity of its opponent. Thus, there is a discrepancy between the perceived and the "true" demand function that the domestic firm faces. The policy intervention is enacted in order to correct for this discrepancy (see Helpman and Krugman, 1989 for a detailed analysis of this issue).

After solving the first order condition (6) we get

$$
s^{C}=\frac{\gamma^{2}}{4\left(2-\gamma^{2}\right)}[(2-\gamma)-2(c-x)+\gamma c]
$$

Whatever the domestic firm's choice of investment strategy, the government will interfere in the market through an output subsidy. The higher the investment effort of the domestic firm, the higher

\footnotetext{
${ }^{11}$ We assume that the government puts equal weight on both the firm's profit and its expenditures for subsidy or in jargon, there is no divergence between the marginal social valuation of corporate profit and subsidy revenue. However, Neary (1994) demonstrates the reasons and the welfare implications when this may not be the case.

12 The second order condition requires $\frac{d^{2} W}{d s^{2}}=\frac{\partial^{2} q^{1}}{\partial s^{2}}(x, s)\left[p^{1}(x, s)-c+x\right]+2 \frac{\partial q^{1}}{\partial s}(x, s) \frac{\partial p^{1}}{\partial s}(x, s)+q^{1}(x, s) \frac{\partial^{2} p^{1}}{\partial s^{2}}(x, s)<0$.

Since $\frac{\partial^{2} q^{1}}{\partial s^{2}}(x, s)=0, \frac{\partial q^{1}}{\partial s}(x, s)>0, \frac{\partial p^{1}}{\partial s}(x, s)<0+\frac{\partial^{2} p^{1}}{\partial s^{2}}(x, s)=0$ this condition is verified.
} 
the payment received from the government. This result is the consequence of a negative relationship between the marginal cost and the subsidy. ${ }^{13}$

As was indicated above, the rationale for subsidy $s^{C}$ is that it allows the firm F1 to commit to the Stackelberg outcome in the quantity game if no subsidy or tax would be in place (see Brander and Spencer, 1985 and Helpman and Krugman, 1989). If the domestic firm tries to increase its quantity and to reach this desirable outcome on its own (instead of the lower Nash profits), it exposes itself to the unstable situation that follows, and therefore risks earning even lower profits than the Nash equilibrium ones. However, if the domestic government interferes in the market through an export subsidy, it alters the perceived unit costs, shifts F1's reaction function outward, and thus provides a new sustainable Nash equilibrium (which coincides with the Stackelberg outcome with no subsidy).

Having solved the last two stages of the game, we can proceed further with the domestic firm's choice of investment level. This decision is based on maximizing the following profit function

$$
\pi^{1}\left(x, s^{C}(x)\right)=\frac{1}{4 \beta\left(2-\gamma^{2}\right)^{2}}[(2-\gamma)(1-c)+2 x]^{2}-k x^{2} .
$$

Therefore, the domestic firm will choose an investment that will reduce its marginal cost with

$$
x_{s}^{C}= \begin{cases}\frac{2-\gamma}{2\left[k \beta\left(2-\gamma^{2}\right)^{2}-1\right]}(1-c) & \text { if } c>\frac{2-\gamma}{2 k \beta\left(2-\gamma^{2}\right)^{2}-\gamma} . \\ c & \text { otherwise }\end{cases}
$$

With such a level of decrease in the unit cost, firm F1 will gain a profit of,

$$
\pi_{s}^{C}=\frac{k(2-\gamma)^{2}}{4\left[k \beta\left(2-\gamma^{2}\right)^{2}-1\right]}(1-c)^{2}
$$

and the welfare in the domestic country will be equal to

$$
W_{s}^{C}=\frac{k(2-\gamma)^{2}\left[k \beta\left(2-\gamma^{2}\right)^{3}-2\right]}{8\left[k \beta\left(2-\gamma^{2}\right)^{2}-1\right]^{2}}(1-c)^{2} \text {. }
$$

The $x_{s}^{C}$ level of the increase in efficiency is higher than its "first-best" counterpart. Let us denote by $\tilde{x}_{s}^{C}$ the first-best socially optimal level of marginal cost reduction that the government would select, were it in a situation to choose $x$ (see section 3 for the first-best outcome obtained in

\footnotetext{
${ }^{13}$ However, Neary (1994) has shown that this negative relationship cannot be unambiguously determined for the general demand function. Nevertheless, the relation holds for linear demand, and under reasonable conditions, for the constant elasticity demand function.
} 
an alternative way). Since $\frac{\partial \pi^{1}}{\partial s} \frac{\partial s}{\partial x}=q^{1} \frac{\gamma^{2}}{2\left(2-\gamma^{2}\right)}>0$ then $\frac{d \pi}{d x}>0$ at $\tilde{x}_{s}^{C}$ and therefore, the firm will choose a higher R\&D level than the first-best optimum. The concrete value of $\tilde{x}_{s}^{C}$ is given by (12):

$$
\widetilde{x}_{s}^{C}= \begin{cases}\frac{2-\gamma}{4 k \beta\left(2-\gamma^{2}\right)-2}(1-c) & \text { if } c>\frac{2-\gamma}{4 k \beta\left(2-\gamma^{2}\right)-\gamma}, \\ c & \text { otherwise }\end{cases}
$$

This is the result of both strategic and manipulatory actions conducted by the domestic firm on the government. The domestic firm invests more compared with the non-strategic benchmark in order to enjoy higher payments from the government and to gain strategic advantages over its competitor. As Leahy and Neary (2000) pointed out, if the government were able to use R\&D policies before investment occurs, it would set up an R\&D tax that will offset exactly this strategic behavior.

Also, it is easy to verify that $x_{f t}^{C}$ is lower than $x_{s}^{C}$ (see Appendix 1, part 1). This is the consequence of F1's manipulatory actions when there is policy intervention: the firm increases investment in order to receive higher payments (subsidies) from the government.

The government's decision to commit or not to free trade is based on the corresponding welfare comparison. This, in turn leads to the condition (13)

$$
k>\frac{2\left(5-2 \gamma^{2}\right)}{\beta\left(2-\gamma^{2}\right)^{3}}=k_{s}^{C} .
$$

Namely, when the R\&D investment is inexpensive, that is, $k<k_{s}{ }^{C}$, it pays to commit to free trade, since the socially wasteful overinvestment is significant and it outweighs the positive benefits of the intervention while the inverse is true when $k>k_{s}{ }^{C}$. Grossman and Maggi 1998 obtained an analogous result for the case of the homogenous goods. ${ }^{14}$ Nonetheless, the new feature here is that the degree of product differentiation affects the critical value of $\mathrm{k}$; the less differentiated the products, the higher $k_{s}{ }^{C}$ is. In other words, free trade is preferred for a given $k$ (and given $\beta$ ) and a high enough $\gamma$ (see Fig 1). To explain this result, we decompose the domestic profit into two parts $\left(\pi^{1}(x)=\pi_{N E T}^{1}(x)+S_{R E V}(x)\right)$; the first part is labeled "the net profit" (and is actually equal to the domestic welfare) while the second part is the subsidy revenue. If the domestic firm were concerned

\footnotetext{
${ }^{14}$ Grossman and Maggi (1998) analyzed the welfare effect of the manipulatory actions of the domestic firm under a similar setup with homogenous products. They noted that, beside the case of expensive R\&D investment, a regime of output subsidy is also optimal in the case of very low R\&D costs. This difference between their result and ours is due to the fact that we find it plausible to ignore the corner solution (that is, zero marginal costs).
} 


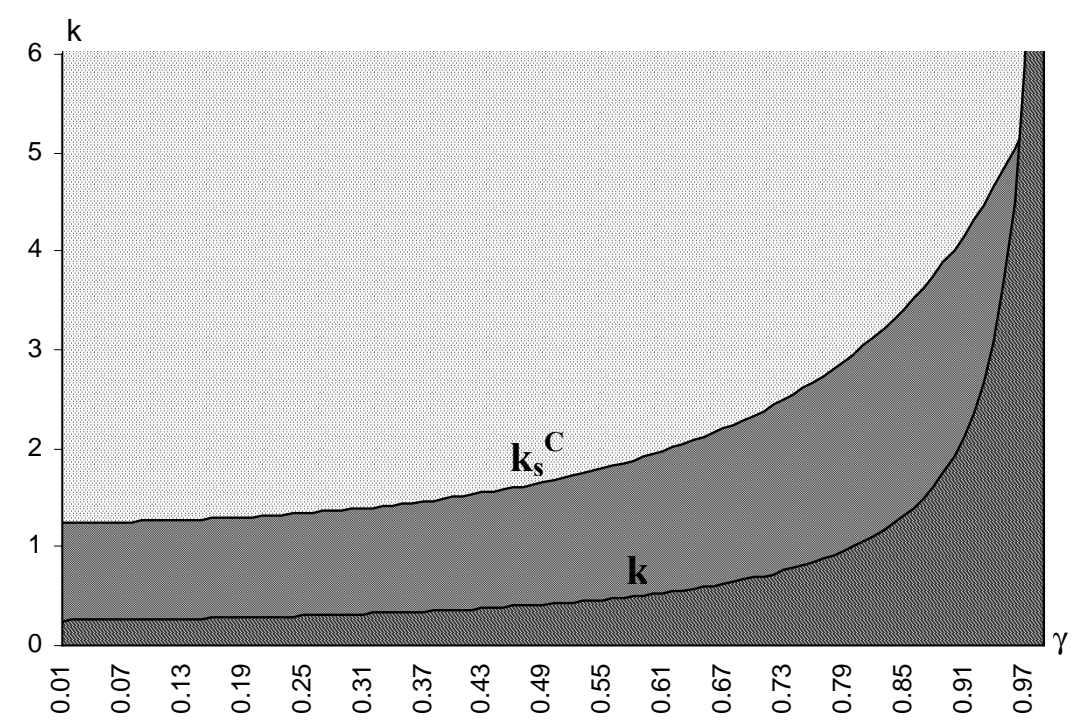

Subsidy $\mathbf{0}$ Free trade Non feasibility

Fig 1. Free Trade versus Intervention -- Respective Parameter Regions of $k$ and $\gamma$ in Cournot competition, $\beta=1$.

only with its net profit and consequently with profit shifting, it would choose a level of decrease in its marginal cost equal to the social optimal one. However, as products become closer substitutes, competition becomes tougher (note that net profit is monotonically declining in $\gamma$ ) and the gain from profit shifting becomes relatively less important. Thus, the subsidy rent as the remaining source of profit becomes crucial as products become less differentiated (note that $\frac{\partial S_{R E V}}{\partial \gamma}>\frac{\partial \pi^{1}}{\partial \gamma}$ ). In other words, as $\gamma$ increases, the major reason for the excessive R\&D investment is not the domestic firm's strategic behavior towards its rival but its manipulative behavior towards the government. Faced with such manipulative behavior the government, constrained to second best policy, may prefer to commit to free trade rather than to allow a wasteful use of social resources. In order to measure the magnitude of this excessive $R \& D$ investment when the government intervenes, we use the difference between the first-best social level of marginal cost reduction, $\tilde{x}_{s}^{C}$, and its second-best counterpart, $x_{s}^{C}$, labeled $D^{I}=x_{s}^{C}-\tilde{x}_{s}^{C}$. When the government does commit to free trade, the corresponding measure is the difference between the first-best and free trade levels, $D^{F T}=x_{f t}^{C}-\tilde{x}_{s}^{C}$ (see Fig 2). The critical value of $\gamma$, labeled $\gamma^{*}$, indicates the switching point from the intervention to the free trade regime. 


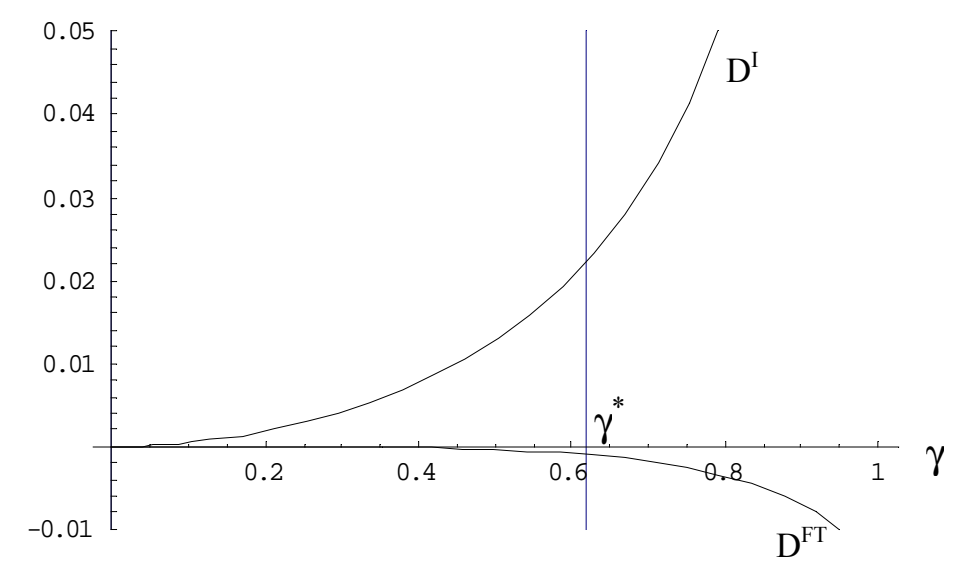

Fig 2. $D^{F T}$ and $D^{I}$ in case $k \beta=3, c=0.4, \gamma^{*}=0.618$.

\subsection{Bertrand Competition}

As in the Cournot case, we will solve the model starting from the last stage. Therefore, the firm's profits are given by

$$
\begin{aligned}
& \pi^{1}\left(p^{1}, p^{2} ; x, s\right)=q^{1}\left(p^{1}, p^{2}\right)\left[p^{1}-(c-x-s)\right]-k x^{2} \\
& \pi^{2}\left(p^{1}, p^{2} ; x\right)=q^{2}\left(p^{1}, p^{2}\right)\left[p^{2}-c\right]
\end{aligned}
$$

where the direct demands are given by (ii).

Since we are looking for a subgame perfect equilibrium, we start our analysis from the last stage. After substituting the direct demands (ii) into the above profit functions and differentiating the resulting functions with respect to the corresponding prices we get the first order conditions:

$$
\begin{aligned}
& (1-\gamma)-\left[2 p^{1}-(c-x-s)\right]+\gamma p^{2}=0 \\
& (1-\gamma)-\left[2 p^{2}-c\right]+\gamma p^{1}=0 .
\end{aligned}
$$

Solving the system (14) - (14') we obtain the inverse demands in terms of the initial parameters $c$ and $\gamma$, and of the choice variables $x$ and $s$

$$
\begin{aligned}
& p^{1}(x, s)=\frac{1}{4-\gamma^{2}}\left[\left(2-\gamma-\gamma^{2}\right)+2(c-x-s)+\gamma c\right] \\
& p^{2}(x, s)=\frac{1}{4-\gamma^{2}}\left[\left(2-\gamma-\gamma^{2}\right)+2 c+\gamma(c-x-s)\right] .
\end{aligned}
$$

Note that both prices are decreasing in $s$ and $x$.

Following (15), (15'), and (ii), the demands for good 1 and good 2 are given by

$$
q^{1}(x, s)=\frac{1}{\beta\left(1-\gamma^{2}\right)\left(4-\gamma^{2}\right)}\left[\left(2-\gamma-\gamma^{2}\right)(1-c)+\left(2-\gamma^{2}\right)(x+s)\right]
$$




$$
q^{2}(x, s)=\frac{1}{\beta\left(1-\gamma^{2}\right)\left(4-\gamma^{2}\right)}\left[\left(2-\gamma-\gamma^{2}\right)(1-c)-\gamma(x+s)\right] .
$$

\subsubsection{Free trade}

When the government opts for no intervention in the very first stage of this game, the domestic firm decides on the level of R\&D investment by maximizing the following profit function

$$
\pi^{1}(x, 0)=\frac{1}{\beta\left(1-\gamma^{2}\right)\left(4-\gamma^{2}\right)^{2}}\left[\left(2-\gamma-\gamma^{2}\right)(1-c)+\left(2-\gamma^{2}\right) x\right]^{2}-k x^{2} .
$$

As a result, this firm will choose an $x$ given by

$$
x_{f t}^{B}= \begin{cases}\frac{\left(2-\gamma-\gamma^{2}\right)\left(2-\gamma^{2}\right)}{k \beta\left(1-\gamma^{2}\right)\left(4-\gamma^{2}\right)^{2}-\left(2-\gamma^{2}\right)^{2}}(1-c) & \text { if } c>\frac{\left(2-\gamma-\gamma^{2}\right)\left(2-\gamma^{2}\right)}{k \beta\left(1-\gamma^{2}\right)\left(4-\gamma^{2}\right)^{2}-\gamma\left(2-\gamma^{2}\right)} . \\ c & \text { otherwise }\end{cases}
$$

Given government commitment to free trade, this level of decrease in marginal cost is socially optimal since in the case of free trade without domestic consumption, the government is interested in maximizing the domestic firm's profit.

With this level of $x$ in place, the firm's profit, and therefore domestic welfare, is given by

$$
\pi_{f t}^{B}=W_{f t}^{B}=\frac{k\left(2-\gamma-\gamma^{2}\right)^{2}}{k \beta\left(1-\gamma^{2}\right)\left(4-\gamma^{2}\right)^{2}-\left(2-\gamma^{2}\right)^{2}}(1-c)^{2} .
$$

\subsubsection{Strategic Trade}

If the government did not commit to free trade, it follows that the welfare maximizing government would intervene by introducing a subsidy or tax program, since it would be ex post optimal. Its decision is based on the following objective function

$$
W(s)=\pi^{1}(x, s)-s q^{1}(x, s)
$$

The above function can be rewritten as

$$
W(s)=q^{1}(x, s)\left[p^{1}(x, s)-(c-x)\right]-k x^{2} .
$$

Much like in (6), the first order condition implies ${ }^{15}$

\footnotetext{
${ }^{15}$ The second order condition requires

$\frac{d^{2} W}{d s^{2}}=\frac{\partial^{2} q^{1}}{\partial s^{2}}(x, s)\left[p^{1}(x, s)-c+x\right]+2 \frac{\partial q^{1}}{\partial s}(x, s) \frac{\partial p^{1}}{\partial s}(x, s)+q^{1}(x, s) \frac{\partial^{2} p^{1}}{\partial s^{2}}(x, s)<0$.

Since $\frac{\partial^{2} q^{1}}{\partial s^{2}}(x, s)=0, \frac{\partial q^{1}}{\partial s}(x, s)>0, \frac{\partial p^{1}}{\partial s}(x, s)<0+\frac{\partial^{2} p^{1}}{\partial s^{2}}(x, s)=0$ the second order condition is verified.
} 


$$
\frac{d W}{d s}=0 \Rightarrow \frac{\partial q^{1}}{\partial s}(x, s)\left[p^{1}(x, s)-c+x\right]=-q^{1}(x, s) \frac{\partial p^{1}}{\partial s}(x, s)
$$

Again, the "distortion" that may trigger the intervention comes from the wedge between perceived and the "true" inverse demand that the domestic firm faces since it does not take into account the impact of its price choice on the price of its opponent in a pure Nash equilibrium (see Helpman and Krugman, 1989).

By solving the equation (20) we obtain the optimal value of subsidy (actually tax, since this level is negative):

$$
s^{B}=\frac{-\gamma^{2}}{4\left(2-\gamma^{2}\right)}[\left(2-\gamma-\gamma^{2}\right)-\left(2-\gamma^{2}\right) \underbrace{(c-x)}_{\text {F1's marginal cost }}+\gamma \underset{\text { F2's marginal cost }}{c}] .
$$

Since $x<c<1$, regardless of the domestic firm's investment level, the subsidy is always negative. Thus, the optimal policy is a tax on output. Its optimal level will be given by $t^{B} \equiv \equiv-s^{B}$.

Again, it is easy to verify that this level $t^{B}$ of tax actually allows the firm F1 to commit to the Stackelberg price in the price game if no subsidy or tax is in place.

Note that the optimal tax $t^{B}$ increases with the increase in $x$, as is easily observed from (21). That is, $d t^{B} / d x>0$, since an increase in $x$ raises the output and enables the government to collect more revenue by charging a higher tax rate. Also, the higher the R\&D investment, the larger the decrease in marginal cost, $x$, and the more severe the subsequent price competition. To soften this detrimental competition, the government uses tax as a "facilitating device" (rather than a profitshifting tool). The domestic firm anticipates the government's action and invests less in R\&D and produces less than without the tax in place.

Firm F1 chooses a level of R\&D that maximizes its own profit

$$
\pi^{1}\left(x, t^{B}(x)\right)=\frac{1}{16 \beta\left(1-\gamma^{2}\right)}\left[\left(2-\gamma-\gamma^{2}\right)(1-c)+\left(2-\gamma^{2}\right) x\right]^{2}-k x^{2} .
$$

After solving the maximization problem for $x_{s}^{B}$ we obtain the optimal decrease in unit cost as a result of $R \& D$ investment for the Bertrand competition:

$$
x_{s}^{B}= \begin{cases}\frac{\left(2-\gamma-\gamma^{2}\right)\left(2-\gamma^{2}\right)}{16 k \beta\left(1-\gamma^{2}\right)-\left(2-\gamma^{2}\right)^{2}}(1-c) & \text { if } c>\frac{\left(2-\gamma-\gamma^{2}\right)\left(2-\gamma^{2}\right)}{16 k \beta\left(1-\gamma^{2}\right)-\gamma\left(2-\gamma^{2}\right)} . \\ c & \text { otherwise }\end{cases}
$$

Consequently, in an interior solution, firm F1 will gain 


$$
\pi_{s}^{B}=\frac{k\left(2-\gamma-\gamma^{2}\right)^{2}}{16 k \beta\left(1-\gamma^{2}\right)-\left(2-\gamma^{2}\right)^{2}}(1-c)^{2},
$$

while the domestic welfare will be

$$
W_{s}^{B}=\frac{k\left(2-\gamma-\gamma^{2}\right)^{2}\left[32 k \beta\left(1-\gamma^{2}\right)-\left(2-\gamma^{2}\right)^{3}\right]}{\left(2-\gamma^{2}\right)\left[16 k \beta\left(1-\gamma^{2}\right)-\left(2-\gamma^{2}\right)^{2}\right]^{2}}(1-c)^{2} .
$$

Note that now the decrease in marginal cost $x_{s}^{B}$ is actually smaller than the corresponding first-best social optimum. To explain this we note that the only difference between the domestic firm's objective function and that of the government's comes from the tax payments $s(x) q^{1}(x, s(x))$. These payments are part of the firm's profits, but not of the social welfare. Let $\tilde{x}_{s}^{B}$ be the first-best socially optimal marginal cost reduction that the government would achieve if it were able to determine the investment level. Since $\frac{\partial \pi^{1}}{\partial s} \frac{\partial s}{\partial x}=-q^{1}\left(p^{1}, p^{2}\right) \frac{\gamma^{2}}{4}<0$ then $\frac{d \pi^{1}}{d x}\left(\tilde{x}_{s}^{B}\right)<0$ and therefore the firm will choose a smaller reduction in marginal cost. The level of the first-best decrease in unit costs is given by

$$
\tilde{x}_{s}^{B}= \begin{cases}\frac{2-\gamma-\gamma^{2}}{8 k \beta\left(1-\gamma^{2}\right)-\left(2-\gamma^{2}\right)}(1-c) & \text { if } c>\frac{2-\gamma-\gamma^{2}}{8 k \beta\left(1-\gamma^{2}\right)-\gamma} . \\ c & \text { otherwise }\end{cases}
$$

As the result of the manipulative actions of the domestic firm towards its government, $\tilde{x}_{s}^{B}>x_{s}^{B}$. The firm decreases its investment in order to pay less tax. If the government were able to use R\&D policies before investment occurs, it would set up an R\&D subsidy that would exactly offset the strategic behavior of the domestic firm and it would induce the domestic firm to choose the marginal cost reduction of $\tilde{x}_{s}^{B}$ (Note that this is the same level of $x$ that the government would select itself, if it had the option of doing so).

It is also straightforward to show that the domestic firm invests more in a free trade environment than it does when an output tax is in place. This means $x_{f t}^{B}$ is higher than $x_{s}^{B}$ (see Appendix 1, part 2). Again, the reason for this is that in case of intervention F1 manipulates the level of tax payments through the level of R\&D investment.

Now it remains only to establish when the domestic government would choose to interfere in the market through a tax on output and when it would prefer to commit to free trade. To accomplish this, we have to determine under which conditions the welfare in the case of taxation (see expression 25) is greater than the welfare in the case of free trade (see expression 19). It follows that only when 


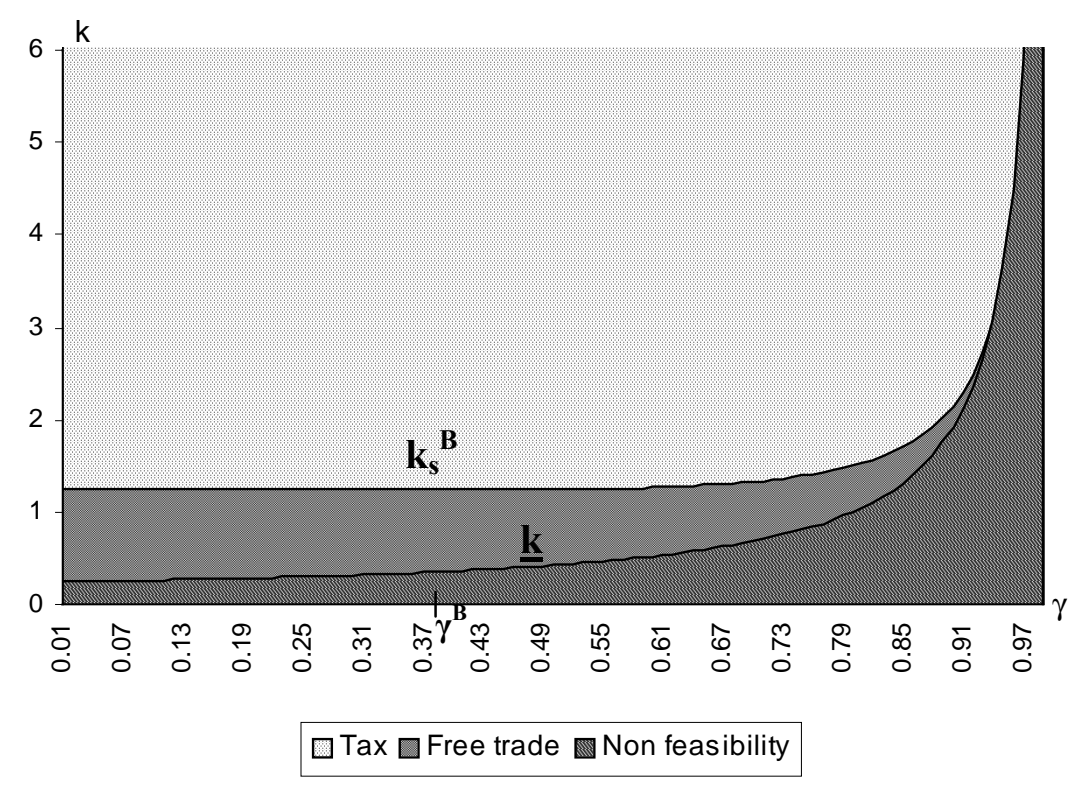

Fig 3. Free Trade versus Intervention -- Respective Parameter Regions of $k$ and $\gamma$ in Bertrand competition, $\beta=1$.

$$
k>\frac{\left(10-\gamma^{2}\right)\left(2-\gamma^{2}\right)^{2}}{32 \beta\left(1-\gamma^{2}\right)}=k_{t}^{B}
$$

does the government levy an output tax. Roughly speaking, when the investment becomes expensive enough, the government interferes in the market (see Fig 3), while the low cost of R\&D investment calls for free trade.

To explain this result we have to recall that in the presence of an output tax, firm F1 reduces its investment in R\&D in order to pay a lower tax. This has a negative impact on the efficiency of firm F1. When the investment is costly enough, even if the firm would ignore the effect of investment on tax it would choose a moderate investment. Moderate investment means moderate tax and therefore, less incentive for the domestic firm to reduce its $R \& D$ in order to manipulate the level of the output tax. As a result, the welfare losses due to manipulatory actions are lower than the increase in the net profits in the presence of a tax. However, this is no longer the case when investment cost is small.

The level of $k$ (given $\beta$ ) is positively related to $\gamma$ after a certain threshold level is reached $\left(\gamma^{c}\right.$ $=0.3971$ ) that is, beyond $\gamma^{\mathrm{B}}$ the less differentiated the products, the higher the critical value of $k$ that delineates the desirability of intervention from the free trade region. Similar to the Cournot case, as competition gets tougher, the contribution of the net profit to the overall increase in profit becomes less significant than the gains following a decrease in the tax payments. 


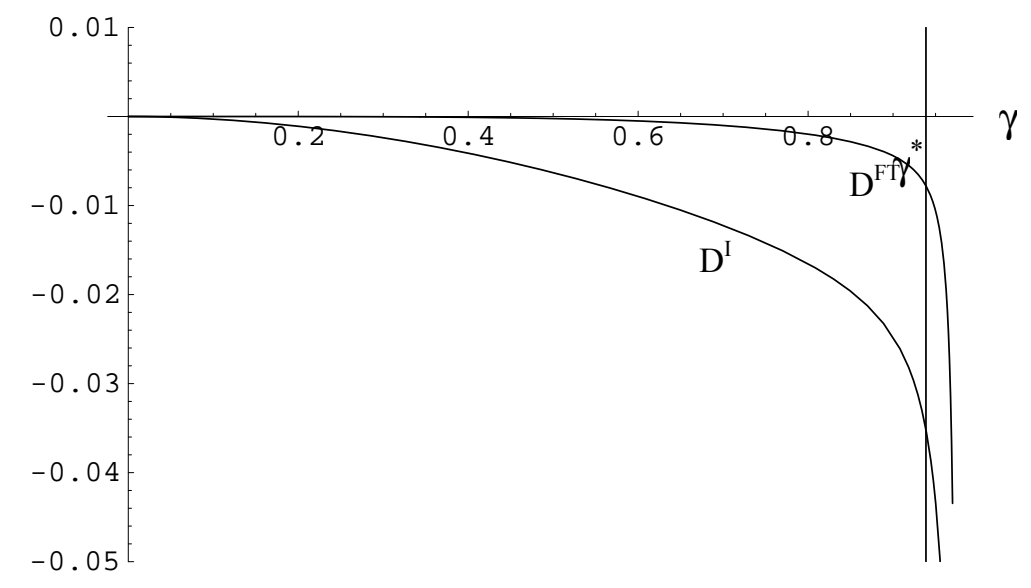

Fig 4. $D^{F T}$ and $D^{I}$ in case $k \beta=3, c=0.4, \gamma^{*}=0.888$.

We can now summarize the main findings of this section.

\section{Proposition 1}

1. Regardless of the type of competition in the market, the domestic firm will choose a positive level of investment in $R \& D$. If the government does not commit to free trade, it will always intervene with an appropriate tax/subsidy scheme. The Cournot firm always invests more in $R \& D$ than its Bertrand counterpart and, consequently, the marginal cost decrease of the Cournot firm is strictly higher than that of the Bertrand firm, that is, $x_{s}^{C}>x_{s}^{B}$.

2. The domestic government will interfere in the market only when the cost parameter of $R \& D$ investment is high enough. If the competition is Bertrand and $k>k_{t}^{B}$ the government will levy an output tax while if the competition is Cournot and $k>k_{s}^{C}$, it will pay an output subsidy. ${ }^{16}$ In addition, critical value $k_{s}^{C}$ is an increasing function of the product differentiation parameter, $\gamma$, on its whole range whereas $k_{t}^{B}$ is an increasing function in $\gamma$ when $\gamma>\gamma^{B}$.

Proof. See Appendix 1 part 3 for a proof of point 1 . All the results in point 2 have already been derived.

\footnotetext{
${ }^{16}$ All the results obtained thus far could be got with the most general linear inverse demands, namely $p^{i}\left(q^{i}, q^{j}\right)=\alpha_{i}-\beta_{i} q^{i}+\delta q^{j}$.
} 


\section{The "First Best" versus the "Second Best" Strategic Trade Policy Under SYMMETRIC INFORMATION}

Before moving to the issue of the asymmetric information, it seems insightful to pause for a while and briefly compare the "second best" policy analyzed here with the "first best" policy (whose detailed derivation can be found in Appendix 2). As was mentioned in the introduction, the "first best" policy in a perfect information framework is comprised of the tax (subsidy) on the R\&D expenditures and the output subsidy (tax) when the market stage competition is of the Cournot (Bertrand) type (see Leahy and Neary 2000).

In the Cournot case, the $R \& D$ tax is aimed at countering overinvestment by the domestic firm that in the adopted setup (in which the government cannot commit inter-temporally) arises for the following two reasons: (i) the strategic, "top dog" behavior of the domestic firm against the foreign firm where the overinvestment leads to higher output, higher profit and higher market share for the domestic firm and (ii) the strategic manipulation of the domestic government by the domestic firm in order to induce higher equilibrium output and consequently higher subsidies. Both of these strategic motives waste scarce resources and thus, represent a harm from the social welfare point of view. As we have already indicated, by implementing the "second best" policy the government is for some reason constrained only to one instrument. In our case this instrument is the output subsidy, so the government is unable to correct the two above described distortions and is thus, exposed to the "overinvestment" manipulation by its own firm. The direct consequence of this is that the second best output subsidy is always higher than the corresponding first best one (see Appendix 2). The most important question here is what is the relative welfare loss of conducting the

Table 1. Percentage differences between domestic welfare under first best and second best policies*

\begin{tabular}{c|cccccccc}
$\gamma / \mathrm{k} \beta$ & 40 & 20 & 10 & 5 & 2.5 & 1.7 & 1.3 & 1.25 \\
\hline 0.05 & 0.000001 & 0.000002 & 0.000004 & 0.000009 & 0.000019 & 0.000032 & 0.000046 & \\
0.15 & 0.000083 & 0.000168 & 0.000345 & 0.000727 & 0.001625 & 0.002668 & 0.003902 & \\
0.25 & 0.000680 & 0.001379 & 0.002834 & 0.005993 & 0.013458 & 0.022217 & \\
0.35 & 0.002875 & 0.005833 & 0.012010 & 0.025490 & 0.057734 & 0.096172 & \\
0.45 & 0.008965 & 0.018214 & 0.037608 & 0.080296 & 0.184275 & 0.311366 & \\
0.55 & 0.023801 & 0.048459 & 0.100486 & 0.216492 & 0.507056 & & \\
0.65 & 0.058033 & 0.118530 & 0.247408 & 0.540580 & 1.308053 & & \\
0.75 & 0.136615 & 0.280448 & 0.591614 & 1.322965 & & & \\
0.85 & 0.323829 & 0.670599 & 1.441118 & 3.361280 & & & \\
0.95 & 0.809675 & 1.705257 & 3.803147 & 9.720324 & & & \\
$*\left(100 \frac{W_{f b}^{C}-W_{s}^{C}}{W_{s}^{C}}=100 \frac{k \beta \gamma^{4}\left(2-\gamma^{2}\right)}{\left[2 k \beta\left(2-\gamma^{2}\right)-1\right]\left[k \beta\left(2-\gamma^{2}\right)^{3}-2\right]}\right)$ & & & & & &
\end{tabular}


second best policy instead of the first best one.

Table 1 displays the discrepancy between the first and the second best policy in terms of the social welfare differences expressed in percentage. The values of the underlying parameters $(k \beta$ and $\gamma$ ) are taken from the region where the (second best) intervention is optimal in both Cournot and Bertrand cases (see Fig. 1 and 3). The relative distortion is low as long as investment cost, $k$ (given $\beta$ ) is large enough, since the over-investment is rather mild and/or as long as products are highly differentiated ( $\gamma$ is small) since the manipulatory behavior is relatively small (see Fig 2). Indeed, the data in Table 1 shows that the relative welfare loss is negligible in this case. When the opposite is true (small $k$ given $\beta$, large $\gamma$ ) the distortion is largest. However, the corresponding data in Table 1 shows that even the largest distortion is around an unimpressive $9.7 \%$.

The first best policy in price competition is a mirror image of the first best policy in the quantity competition. $R \& D$ is subsidized to counter the strategic, under-investment of the domestic firm that in our setup stems from the two related reasons above, that is: (i) strategic "puppy dog" behavior of the domestic firm towards the foreign firm where the underinvestment leads to milder price competition and higher profit for the domestic firm and (ii) the strategic manipulation of the domestic government by the domestic firm in order to induce lower output and consequently fewer tax payments. Again, the direct consequence of the domestic firm's behavior in the case of second best policy is that it manages to pay lower tax than in the case of the first best policy (see Appendix 2). Much like in the Cournot case the relative welfare distortion is negligible when investment costs are large and the degree of product differentiation is small, while it monotonically increases when $k \beta$ decreases and/or $\gamma$ increases (see Table 2).

Table 2. Percentage differences between domestic welfare under first best and second best policy*

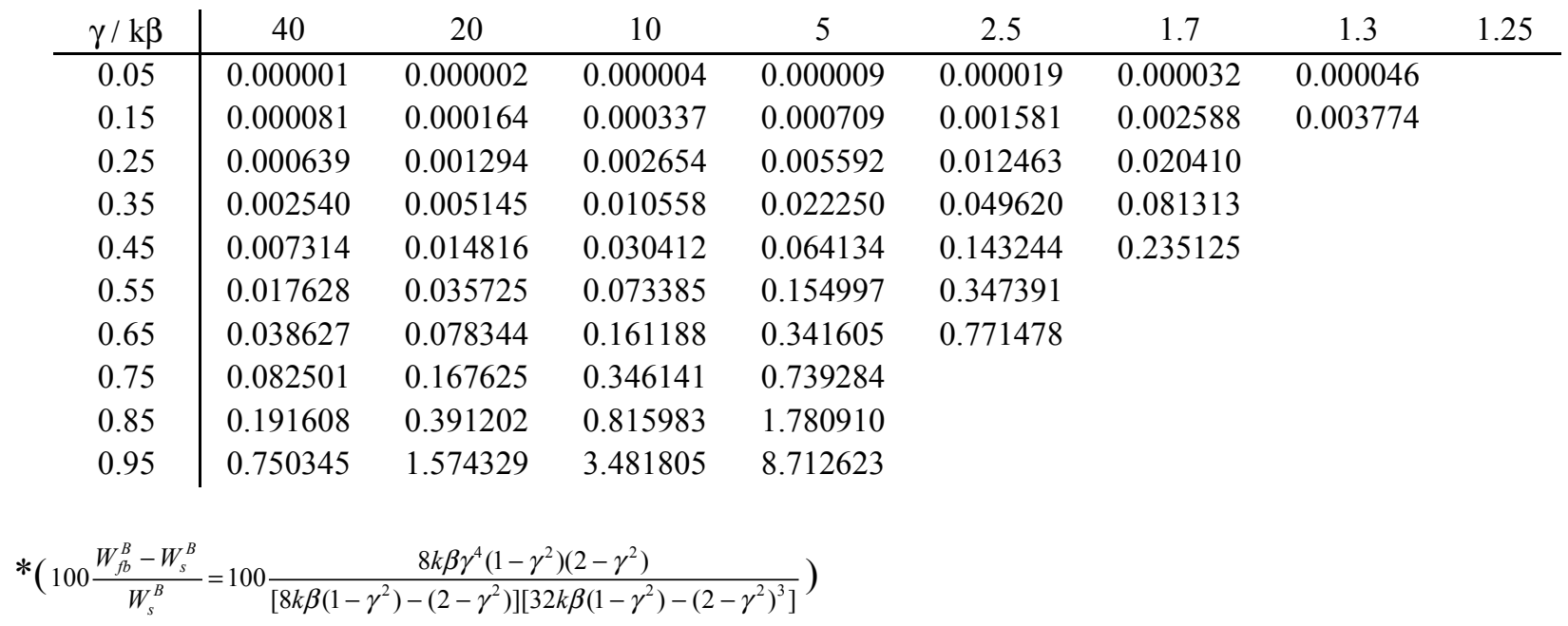




\section{The Model - THE ASYMmetric INFORMATION CASE}

In order to isolate the consequences of the uncertainty of the mode of competition on the optimal design of the strategic intervention, we now assume that the only missing information for the government is the type of market interaction between the domestic and foreign firm. This assumption leads us to modifying the timing of the symmetric information model somewhat: first the nature moves and chooses the type of market interaction. With probability $\eta$ it will choose Bertrand competition, and with 1- $\eta$ Cournot competition where $\eta$ is assumed to be a common knowledge $^{17}$. Next, the domestic government will announce whether it will commit to free trade or not. Non-commitment implies that the government would interfere in the market through output subsidies (taxes if these subsidies are negative). Based on the government's announcement, the domestic firm will choose the level of R\&D investment. After investment has occurred, the "noncommitted" government will establish the appropriate level of trade policy. Finally, competition in the market takes place.

If the government does not commit to free trade, it pays attention to the level of marginal cost reduction, $x$, chosen by the domestic firm. Based on this, the government may update its prior probability $\eta$ and infer the type of competition in the market. However, since the domestic firm will correctly predict it, it may be beneficial for the firm to mislead the government. More precisely, it is possible that the Bertrand firm mimics the behavior of a Cournot firm and chooses higher R\&D than otherwise in order to benefit from the government's help rather than pay a tax. ${ }^{18}$ Thus, in the asymmetric information setup the government might also be subject to manipulation by the domestic firm. Such actions are costly from the social point of view and may further decrease the desirability of a trade policy. In order to avoid such actions, the government can commit itself to free trade. However, this would imply foregoing the benefits from profit shifting.

We start the analysis of the equilibria of the game with the government's decision of intervention vs. free trade. The government will compare

$$
\begin{aligned}
& E W_{f t}=\eta W_{f t}^{B}+(1-\eta) W_{f t}^{C} \\
& E W_{s t}=\eta W_{s t}^{B}+(1-\eta) W_{s t}^{C}
\end{aligned}
$$

and will choose the policy which will bring the highest expected welfare.

From Section 2 we know the levels of welfare under the free trade regime for each of the

\footnotetext{
${ }^{17}$ However, Maggi (1996) has demonstrated that the type of competition arises endogenously in a capacity-price game ranging from the Bertrand to the Cournot outcome, as capacity constraints become more important.

${ }^{18}$ Note that the domestic firm's profits are increasing in the level of subsidy, regardless of the type of market competition.
} 
market interaction types, e.g. Bertrand (welfare given by (5)) and Cournot (where welfare is given by (19)). Hence, the expected welfare without government intervention is given by

$$
E W_{f t}=k(1-c)^{2}\left(\eta \frac{\left(2-\gamma-\gamma^{2}\right)^{2}}{k \beta\left(1-\gamma^{2}\right)\left(4-\gamma^{2}\right)^{2}-\left(2-\gamma^{2}\right)^{2}}+(1-\eta) \frac{(2-\gamma)^{2}}{k \beta\left(4-\gamma^{2}\right)^{2}-4}\right)
$$

When the government does not commit to free trade, the domestic firm competing in the Cournot manner may prefer to convey its type to the government, and hence to qualify for subsidies rather than pay tax. However, a Bertrand firm may find it optimal to mimic the behavior of a Cournot firm in order to enjoy the government's assistance in the form of output subsidies. If this is the case, we can expect the Cournot firm to incur some extra-investment costs to signal its type by a "large" marginal cost decrease, $x$, (or equivalently, high level of R\&D investment) where "large" is defined as the level of $x$ that is unprofitable for the Bertrand firm to undertake even when it is perceived as Cournot. When such a signaling strategy is not too expensive and its costs are more than offset by the augmentation in profits due to output subsidies, we will end up with a separating equilibrium configuration in the market.

\section{Separating equilibrium}

We look for separating Perfect Bayesian equilibria in which the Cournot firm would find it optimal to signal its type by adopting a higher increase in efficiency than it would undertake in the full-information case. Let us denote

$$
\begin{gathered}
\pi_{p}^{r}\left(s^{p}(x), x\right)=q^{1}(x)\left[p^{1}(x)-\left(c-x-s^{p}(x)\right)\right]-k x^{2} \\
\text { where } s^{p}(x)=\arg \max _{s} W^{p}(x, s) .
\end{gathered}
$$

This is the profit that a domestic firm, which has invested $k x^{2}$ in $\mathrm{R} \& \mathrm{D}$, competes $a \grave{a}$ la $r$, and is perceived by government as $p$, will get ( $r$ and $p$ stand for either Cournot or Bertrand). Let also

$$
\begin{aligned}
\bar{\pi}_{p}^{r} & =\max _{x} \pi_{p}^{r}\left(s^{p}(x), x\right), \\
\bar{x}_{p}^{r} & =\arg \max _{x} \pi_{p}^{r}\left(s^{p}(x), x\right) .{ }^{19}
\end{aligned}
$$

Then, the set of separating equilibria are given by all pairs $\left(\bar{x}_{B}^{B}, x_{C}\right)$ such that $x_{C}$ satisfies

$$
\begin{aligned}
& \bar{\pi}_{B}^{B} \geq \pi_{C}^{B}\left(s^{C}\left(x_{C}\right), x_{C}\right) \\
& \pi_{C}^{C}\left(s^{C}\left(x_{C}\right), x_{C}\right) \geq \bar{\pi}_{B}^{C}
\end{aligned}
$$

and the government's beliefs:

\footnotetext{
${ }^{19}$ With these new notations, $\bar{x}_{B}^{B}=x_{s}^{B}$ and $\bar{x}_{C}^{C}=x_{s}^{C}$.
} 


$$
\left\{\begin{array}{l}
x_{C} \text { - Cournot type of competition } \\
\forall x \neq x_{C} \text { - Bertrand type of competition }
\end{array}\right.
$$

The first condition prevents a Bertrand firm from mimicking the behavior of a Cournot firm by undertaking the same level of $\mathrm{R} \& \mathrm{D}$ whereas the last condition ensures that a firm competing $a$ la Cournot would be better off by revealing its type through signaling than being perceived as a Bertrand firm.

In such separating equilibria, a Bertrand firm cannot do better than choosing its optimal value $\bar{x}_{B}^{B}=x_{s}^{B}$. Therefore, the welfare, in the case of nature choosing Bertrand competition, is the same in separating equilibria as in the perfect information equilibrium. However, this will not be the case for Cournot market competition. A Cournot firm will have to signal its type by incurring some additional costs. This result is captured in the following lemma.

LEMMA 1 The full-information outcome cannot be supported as a separating equilibrium, that is, $\bar{\pi}_{B}^{B} \leq \pi_{C}^{B}\left(s^{C}\left(\bar{x}_{C}^{C}\right), \bar{x}_{C}^{C}\right)$.

Proof. See Appendix 3.

The above lemma points out that in a separating equilibrium it would be necessary that $x_{C}>\bar{x}_{C}^{C}$. However, this lemma says nothing regarding the existence of such an equilibrium. It might be the case that whatever the level of desired increase in efficiency a Cournot firm is willing to pursue, a Bertrand firm may find it profitable to mimic the Cournot firm in order to qualify for output subsidies instead of paying output taxes. Nevertheless, in the separating equilibrium (if it exists), a Cournot firm would invest in R\&D more than it does in a full information setup with government intervention. This implies that the socially wasteful overinvestment will be even greater than it is in the analogous full-information case.

Since neither the expected welfare in the free trade regime nor the welfare under Bertrand competition are altered by the government's knowledge regarding the market structure, the above considerations imply that an uninformed government will on average interfere less than an informed one.

We now proceed to characterize the separating equilibrium.

\section{Proposition 2}

1. A separating equilibrium exists provided that the goods in question are not "too close" substitutes, and provided that the R\&D costs of investment ( $k$ ) are not "too low".

2. If there is a separating equilibrium and competition is of the Cournot type, the commitment to 
free trade would always yield higher social welfare than government intervention in form of an output subsidy. A domestic government would therefore interfere in the market only if it has high expectations that the competition in the market takes place à la Bertrand (high level of $\eta$ ) and the investment costs, $k$, are such that $k>k_{t}^{B}$.

In part 1 of the above proposition, the existence of the separating equilibrium depends on the relations between the corresponding profit functions $\pi_{p}^{r}\left(s^{p}(x), x\right)$. It follows that the necessary (s1) and sufficient (s2) conditions for a separating equilibrium to exist are

$$
\pi_{B}^{B}<\pi_{B}^{C}<\pi_{C}^{B}<\pi_{C}^{C}
$$

and (s2)

there is an interval $\left(x_{l}, x_{h}\right)$ such that

$$
\begin{aligned}
& \bar{\pi}_{B}^{B}=\pi_{C}^{B}\left(s^{C}\left(x_{l}\right), x_{l}\right) \\
& \pi_{C}^{C}\left(s^{C}\left(x_{h}\right), x_{h}\right)=\bar{\pi}_{B}^{C}
\end{aligned}
$$

and $x_{l}<x_{h}$ (see Fig 5).

More precisely, the ranking $\pi_{B}^{B}<\pi_{B}^{C}<\min \left\{\pi_{C}^{B}, \pi_{C}^{C}\right\}^{20}$ holds regardless of the value of the parameter requirement. However, as soon as $\gamma<0.9783$, implying that goods are not "too close" substitutes and $k$ exceeds certain critical value $k^{*}$, the ranking (s1) applies (see Appendix 4, point 3). ${ }^{21}$ Moreover, as soon as $\gamma<0.9257$ the sufficient conditions (s2) hold for values of $k$ higher than a certain critical level $k^{* *}$ (see Appendix 4, point 4). ${ }^{22}$ This last situation can be considered the general case since the concavity of the underlying utility function requires $\gamma<1$ and the feasibility argument requires higher $k$ for higher $\gamma$ (see Fig 1).

Given beliefs (32) and the necessary conditions (s1) for the existence of a separating equilibrium, then $x_{C}$ such that $x_{l}<x_{C}<x_{h}$ can be supported in a separating equilibrium as ensured by the sufficient condition (s2) (see Fig 5). The existence of the interval $\left(x_{l}, x_{h}\right)$ is proved by means

\footnotetext{
${ }^{20}$ See Appendix 4 for the proof of this relation (point 1) and of $\bar{\pi}_{B}^{B}<\bar{\pi}_{B}^{C}$ (point 2).

${ }^{21}$ When $1>\gamma>0.9783$, so that products are very alike, a Bertrand firm perceived as Cournot, earns higher profit than a correctly identified Cournot firm for all levels of $\mathrm{x}$, that is $\pi_{C}^{B}(x)>\pi_{C}^{C}(x)$. This is the consequence of tougher competition in the Bertrand case, so that the R\&D investment leads to higher output and higher market share resulting in higher subsidy revenue and higher total profit for the Bertrand firm.

${ }^{22}$ Whenever the products are quite alike so that $0.9783>\gamma>0.9257$, a Bertrand firm can successfully mimic the behaviour of a Cournot firm (since it is too costly for a firm competing in quantities to differentiate itself through high enough levels of investment). Even when the cost of R\&D is very high, a Bertrand firm would opt for high levels of investment and therefore high R\&D costs and output subsidies, rather than for harsh competition combined with output
} 
of a simulation technique.

However, as stated in part 2 of Proposition 2, the fact that such equilibrium exists offers no guarantee that the government will opt for it. Since the overinvestment in the case of asymmetric information is always larger than it is in the symmetric information case (that is, $x_{C}>\bar{x}_{C}^{C}$ ), the expected welfare in a separating equilibrium under an output policy regime is always smaller than in the corresponding full information case. Thus, for all the parameters for which a fully informed government opts for free trade regardless of the market structure, a government facing information asymmetry would opt for free trade as well. In order to identify all the ranges of parameters for which free trade is the optimal policy under asymmetric information, we have to compare the expected welfare in case of non-intervention (30) with that of government intervention. The latter one can be computed from formula (29), where

$$
\begin{aligned}
& W_{s t}^{B}=\frac{k(1-c)^{2}(1-\gamma)^{2}(2+\gamma)^{2}\left[32 k \beta\left(1-\gamma^{2}\right)-\left(2-\gamma^{2}\right)^{3}\right]}{\left(2-\gamma^{2}\right)\left[16 k \beta\left(1-\gamma^{2}\right)-\left(2-\gamma^{2}\right)^{2}\right]^{2}}=W_{s}^{B}, \text { and } \\
& W_{s t}^{C}=\frac{\left[(1-c)(2-\gamma)+2 x_{C}\right]^{2}-8 k \beta x_{C}{ }^{2}\left(2-\gamma^{2}\right)}{8 \beta\left(2-\gamma^{2}\right)}<W_{s}^{C} .
\end{aligned}
$$

As obtained through the computer simulation, in a separating equilibrium, the social welfare under free trade is always higher than the welfare in the Cournot separating equilibrium.

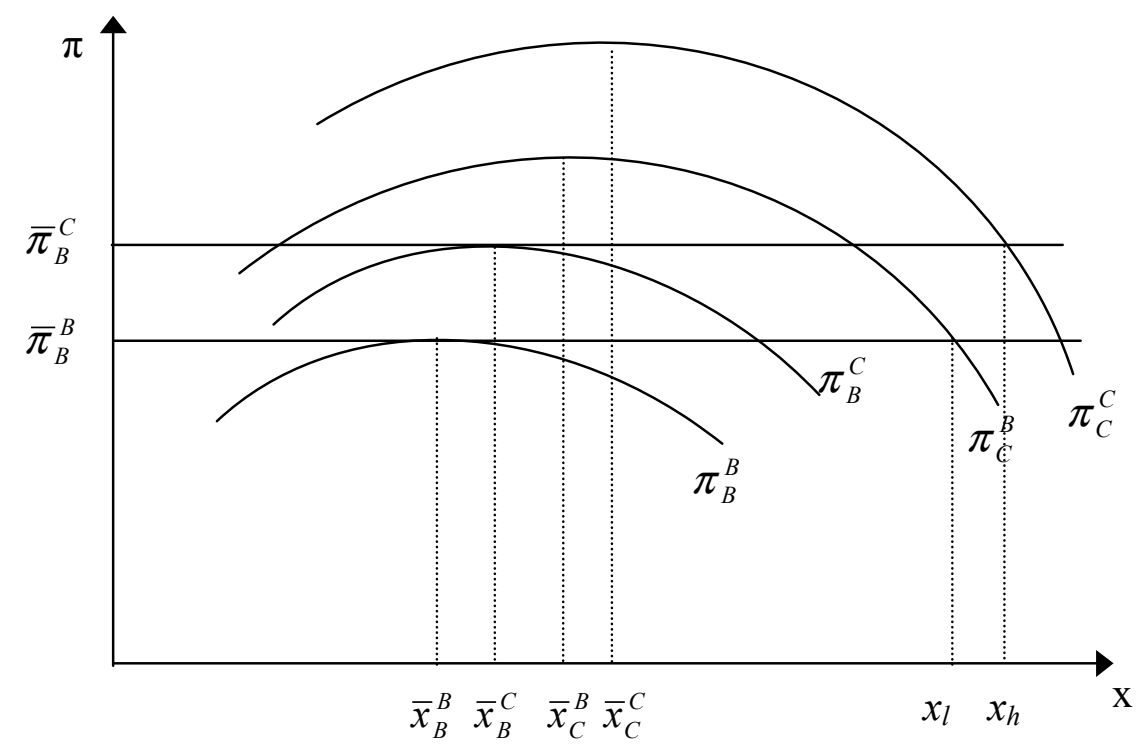

Fig 5. The Necessary Relationship between Profits for the Existence of a Separating Equilibrium ${ }^{23}$ 
To sum up, it is optimal to intervene only when the competition in the market is very likely to be Bertrand and $k$ exceeds the critical level $k_{t}^{B}$ even though a separating equilibrium exists for a wide range of parameters. This is a consequence of the socially costly signaling. Due to the strategic behavior towards the rival and the possibility of manipulation in a perfect information setup, a Cournot firm incurs higher investment than is socially optimal. The presence of asymmetric information and the need for signaling drive the investment even further from the socially desirable level. Moreover, a tax policy for a Bertrand firm increases its incentives to mimic the behavior of a Cournot one. All these actions and incentives drive the welfare with asymmetric information in case of Cournot competition below the free trade level.

\section{ConClusions}

In this paper, we put forward a simple yet realistic variant of the so called "third market" model, in which foreign and domestic firms compete in either quantity or price in a third market and the domestic government is bound to intervene only after the realization of the domestic firm's strategic variable (R\&D investment in our case) takes place. This setup implies that the domestic government is unable to commit inter-temporally to the output policy allowing the domestic firm to manipulate the government through the chosen level of $R \& D$ since it foresees that the welfare maximizing government will find it optimal to intervene ex post. Such manipulative behavior results in a socially inefficient level of R\&D investment and thus, may induce the government to consider commitment to free trade as a device to prevent this kind of strategic behavior of the domestic firm. In a sense, the government is constrained to choosing between two "second best policies": i.e. ex post strategic trade intervention versus free trade. The former enables the domestic firm to achieve the Stackelberg outcome vis-à-vis its rival and enjoy the benefits of profit shifting while society's welfare declines due to the firm's inappropriate investment level. The latter option sacrifices profit shifting gains in order to avoid the either socially excessive (Cournot competition) or socially insufficient (Bertrand competition) R\&D investment. Both policies fall short of the "first best" ideal which requires the government to have, apart from the output policy, an R\&D policy instrument before the firm's investment is made.

The above notions of both the first and the second best intervention are defined in the framework of symmetric, perfect information setup. The only purpose of the first best policy outcome is to serve as a relevant benchmark, while the main focus of the analysis is on the more

bigger than $\bar{x}_{C}^{C}$ (Upon request we can provide a discussion of the ranking of the optimal values depending on the parameters). Whatever the relationship between these values, as long as the relationship between profits remain as in Fig. 5, a separating equilibrium exists. 
realistic second best policy that seems especially suitable when we consider the case of asymmetric information.

In terms of relevant results under the assumptions of perfect information and the second best policy framework, we found that the standard results in which firms competing in prices underinvest in $R \& D$ while firms competing in quantities overinvest in $R \& D$ are reinforced in our setup due to the manipulative behavior of the domestic firm. Further, Grossman and Maggi's (1998) find that government intervention is optimal for high unit R\&D investment costs, $k$, extends to our setup with product differentiation and moreover is valid for both Cournot and Bertrand types of competition. Thus, a perfectly informed government will implement an output policy (regardless of the type of market competition) whenever the cost parameter of $R \& D$ investment, $k$, is high enough while free trade will be optimal when $k$ is low. The new feature here is the role of product differentiation on the key policy choice between free trade and strategic trade policy; namely, the less differentiated the products, the higher the critical level of $k$ above which the strategic trade policy is optimal. The intuition for this result stems from the consequence of the relevant comparison of the second best policy with the first best one. In the case of Cournot competition, the portion of the profit from subsidy revenue tends to increase as products become more homogeneous and to become more important on margin than the portion of the profit from output revenue. As a consequence, as product differentiation decreases, the firm has an incentive to increase already excessive (with respect to the corresponding first best value) investment in R\&D in order to enhance its profit from subsidy. This in turn leads to ever-larger deviation from the first best welfare, and so free trade becomes optimal when products become closer substitutes. More precisely, given the $\mathrm{R} \& \mathrm{D}$ cost parameter $k$, there is a critical switching point in the degree of product differentiation at which free trade is preferred to strategic intervention. Analogously, in the Bertrand case already insufficient R\&D investments (from the first best policy point of view) decrease as products become less differentiated (given that $\gamma>\gamma^{\mathrm{B}}$ ) since on the margin the relevant gain in profit is achieved by cutting taxes via a reduction in R\&D investment and not through the market competition. Thus, again commitment to free trade becomes optimal as, given $k$ and $\beta$, the decline in the degree of product differentiation reaches the critical point. Finally, in the perfect information setup, the welfare losses of the "second best" policy relative to the first best policy are generally small as Table 1 and 2 demonstrate.

As for asymmetric information, there is an additional social cost that arises from the signaling when the government does not commit to free trade and the competition on the market is of the Cournot type. This effect manifests itself through even greater overinvestment compared with the corresponding case of the perfect information to the extent that it makes the intervention always more costly than free trade in terms of social welfare loss. Thus, the free trade seems to be a robust 
policy choice as conjectured by Paul Krugman (Krugman, 1987) and the imperfectly informed government opts for free trade in general unless the probability of Cournot competition is rather "small" and the unit cost of investment is "large enough" to justify the intervention. Moreover, free trade has a special role in the given setup, a role that is distinctive from the traditional argument favoring free trade. That is, it may serve, irrespectively of whether the information is symmetric or not, as a device that protects the government from the manipulating and socially inefficient behavior of domestic firms. 


\section{APPENDIX 1}

1. Since $c>\frac{2-\gamma}{2 k \beta\left(2-\gamma^{2}\right)^{2}-\gamma}, \quad x_{f t}^{C}=\frac{2-\gamma}{2\left[k \beta\left(\frac{4-\gamma^{2}}{2}\right)^{2}-1\right]}(1-c) \quad$ and $\quad x_{s}^{C}=\frac{2-\gamma}{2\left[k \beta\left(2-\gamma^{2}\right)^{2}-1\right]}(1-c)$. Because $\frac{4-\gamma^{2}}{2}>2-\gamma^{2}$ the denominator of $x_{f t}^{C}$ is bigger than that of $x_{s}^{C}$ and therefore $x_{s}^{C}>x_{f t}^{C}$.

2. Since $\quad c>\frac{2-\gamma}{2 k \beta\left(2-\gamma^{2}\right)^{2}-\gamma}, \quad x_{f t}^{B}=\frac{\left(2-\gamma-\gamma^{2}\right)\left(2-\gamma^{2}\right)}{k \beta\left(1-\gamma^{2}\right)\left(4-\gamma^{2}\right)^{2}-\left(2-\gamma^{2}\right)^{2}}(1-c) \quad$ and $x_{s}^{B}=\frac{\left(2-\gamma-\gamma^{2}\right)\left(2-\gamma^{2}\right)}{16 k \beta\left(1-\gamma^{2}\right)-\left(2-\gamma^{2}\right)^{2}}(1-c)$. Because $\left(4-\gamma^{2}\right)^{2}<16$ the denominator of $x_{f t}^{B}$ is smaller than that of $x_{s}^{B}$ and therefore $x_{s}^{B}<x_{f t}^{B}$.

3. We have to prove that $x_{s}^{B}<x_{s}^{C}$. All the other results in this proposition were already discussed and proved before.

$$
x_{s}^{C}-x_{s}^{B}=\gamma^{2}(1-c)^{2} \frac{2 k \beta\left(16-4 \gamma-24 \gamma^{2}+6 \gamma^{3}+8 \gamma^{4}-\gamma^{5}-\gamma^{6}\right)-\gamma\left(2-\gamma^{2}\right)}{2\left[k \beta\left(2-\gamma^{2}\right)^{2}-1\right]\left[16 k \beta\left(1-\gamma^{2}\right)-\left(2-\gamma^{2}\right)^{2}\right]} .
$$

Since $16-4 \gamma-24 \gamma^{2}+6 \gamma^{3}+8 \gamma^{4}-\gamma^{5}-\gamma^{6}>0$ for all $\gamma$ on $(0,1)$, the numerator of the above expression is an increasing function on $k$. If at $\underline{k}$ this numerator is positive, it follows that for all the range of possible $k$ it will be positive. At $\underline{k}$ this numerator equals

$$
\frac{64+32 \gamma-104 \gamma^{2}-36 \gamma^{3}+56 \gamma^{4}+10 \gamma^{5}-12 \gamma^{6}-\gamma^{7}+\gamma^{8}}{(2+\gamma)\left(2-\gamma^{2}\right)^{2}}
$$

Since $64+32 \gamma-104 \gamma^{2}-36 \gamma^{3}+56 \gamma^{4}+10 \gamma^{5}-12 \gamma^{6}-\gamma^{7}+\gamma^{8}>0$ for all $\gamma$ on $(0,1)$, the numerator in expression (a) is positive for all feasible $k$ s. Moreover, $\gamma^{2}(1-c)^{2}$ and the denominator of the above mentioned expression are positive as well. Therefore $x_{s}^{B}<x_{s}^{C}$. 
The first-best policy implies the following timing: the domestic government commits to the tax (subsidy), $t$, on R\&D investment in the first stage. Following this decision, the domestic firm invests in R\&D. Based on the firm's choice, the government sets the level of subsidy (tax), s, on the domestic output. Finally, the firms compete in either output or price on the third market.

\section{Cournot Competition}

In the last stage, the domestic firm's maximization problem is given by

$$
\pi^{1}\left(q^{1}, q^{2} ; x, s, t\right)=q^{1}\left[p^{1}\left(q^{1}, q^{2}\right)-(c-x-s)\right]-k(1+t) x^{2} .
$$

The level of $t$ has no influence on firms' reaction functions and therefore demands are still given by (2) and (2').

The government chooses the level of the output policy that maximizes

$$
W(s, t)=\pi^{1}(x, s, t)-s q^{1}(x, s)+t k \beta x^{2} .
$$

Again, the level of $t$ has no influence on the first derivative of this objective function, thus the government will choose a subsidy $s_{S, t}{ }^{C}=s^{C}$ given by formula (7). As a result, the domestic firm's profit function will be

$$
\pi^{1}\left(x, s^{C}(x), t\right)=\frac{1}{4 \beta\left(2-\gamma^{2}\right)^{2}}[(2-\gamma)(1-c)+2 x]^{2}-k(1+t) x^{2} .
$$

The level of increase in efficiency, $x$, that maximizes the above function is given by

$$
x_{s, t}^{C}=\frac{2-\gamma}{2\left[(1+t) k \beta\left(2-\gamma^{2}\right)^{2}-1\right]}(1-c) \text {. }
$$

Finally, the government chooses the level of tax based on the following objective function

$$
W_{s, t}^{C}=\frac{k(2-\gamma)^{2}\left[(1+t)^{2} k \beta\left(2-\gamma^{2}\right)^{3}-2\right]}{8\left[(1+t) k \beta\left(2-\gamma^{2}\right)^{2}-1\right]^{2}}(1-c)^{2} .
$$

The optimal level of R\&D tax is given by

$$
t_{s, t}^{C}=\frac{\gamma^{2}}{2-\gamma^{2}} .
$$

The first-best level of marginal cost reduction and corresponding domestic welfare are: 


$$
x_{s, t}^{C}=\frac{2-\gamma}{2\left[2 k \beta\left(2-\gamma^{2}\right)-1\right]}(1-c), \quad W_{s, t}^{C}=\frac{k(2-\gamma)^{2}}{4\left[2 k \beta\left(2-\gamma^{2}\right)-1\right]}(1-c)^{2} .
$$

Now we can compare the optimal level of increase in efficiency under the first-best policy $\left(x_{s, t}{ }^{C}\right)$ with that under the second-best policy $\left(x_{s}{ }^{C}\right)$. Afterwards, we can immediately compare the level of subsidies under these two different policies.

$$
\text { Since } c>\frac{2-\gamma}{2 k \beta\left(2-\gamma^{2}\right)^{2}-\gamma}, \quad x_{s}^{C}=\frac{2-\gamma}{2\left[k \beta\left(2-\gamma^{2}\right)^{2}-1\right]}(1-c) \text {. Because } 2\left(2-\gamma^{2}\right)>\left(2-\gamma^{2}\right)^{2}
$$

the denominator of $x_{s, t}^{C}$ is bigger than that of $x_{s}^{C}$ implying $x_{s}^{C}>x_{s, t}^{C}$. Finally, recalling that the subsidy is an increasing function of $x$, implies that a higher subsidy will be paid under a second-best policy.

\section{Bertrand Competition}

At the price competition stage, the domestic firm's maximization problem is given by

$$
\pi^{1}\left(p^{1}, p^{2} ; x, s, t\right)=q^{1}\left(p^{1}, p^{2}\right)\left[p^{1}-(c-x-s)\right]-k(1+t) x^{2} .
$$

The level of $t$ has no influence on firms' reaction functions so the inverse demands as a function of $x$ and $s$ are given by (15) and (15').

The government chooses the level of the output policy that maximizes

$$
W(s, t)=\pi^{1}(x, s, t)-s q^{1}(x, s)+t k \beta x^{2} .
$$

As was the case under Cournot competition, the level of $t$ has no influence on the level of output policy (which is actually a tax), so $s_{s, t}^{B}=s^{B}$ and is given by formula (21). As a result, domestic firm's profit is

$$
\pi^{1}\left(x, s_{s, t}^{B}(x), t\right)=\frac{1}{16 \beta\left(1-\gamma^{2}\right)}\left[\left(2-\gamma-\gamma^{2}\right)(1-c)+\left(2-\gamma^{2}\right) x\right]^{2}-k(1+t) x^{2}
$$

and it will choose a level of $x$

$$
x_{s, t}^{B}=\frac{\left(2-\gamma-\gamma^{2}\right)\left(2-\gamma^{2}\right)}{16(1+t) k \beta\left(1-\gamma^{2}\right)-\left(2-\gamma^{2}\right)^{2}}(1-c) .
$$

Finally, the government selects the level of R\&D subsidy based on the following objective function

$$
W_{s, t}^{B}=\frac{k\left(2-\gamma-\gamma^{2}\right)^{2}\left[32(1+t)^{2} k \beta\left(1-\gamma^{2}\right)-\left(2-\gamma^{2}\right)^{3}\right]}{\left(2-\gamma^{2}\right)\left[16(1+t) k \beta\left(1-\gamma^{2}\right)-\left(2-\gamma^{2}\right)^{2}\right]^{2}}(1-c)^{2} .
$$

The optimal level of R\&D policy, which is a subsidy, is given by 


$$
t_{s, t}^{B}=-\frac{\gamma^{2}}{2} .
$$

The first-best level of marginal cost reduction and corresponding domestic welfare are:

$$
x_{s, t}^{B}=\frac{2-\gamma-\gamma^{2}}{8 k \beta\left(1-\gamma^{2}\right)-\left(2-\gamma^{2}\right)}(1-c), \quad W_{s, t}^{B}=\frac{k\left(2-\gamma-\gamma^{2}\right)^{2}}{\left(2-\gamma^{2}\right)\left[8 k \beta\left(1-\gamma^{2}\right)-\left(2-\gamma^{2}\right)\right]}(1-c)^{2} \text {. }
$$

Now we can compare the optimal level of increase in efficiency under the first-best policy $\left(x_{s, t}^{B}\right)$ with that under the second-best policy $\left(x_{s}^{B}\right)$.

Since $c>\frac{2-\gamma}{2 k \beta\left(2-\gamma^{2}\right)^{2}-\gamma}, x_{s}^{B}=\frac{2-\gamma-\gamma^{2}}{16 k \beta \frac{1-\gamma^{2}}{2-\gamma^{2}}-\left(2-\gamma^{2}\right)}(1-c)$. Because $16 \frac{1-\gamma^{2}}{2-\gamma^{2}}>8\left(1-\gamma^{2}\right)$ the denominator of $x_{s, t}^{B}$ is smaller than that of $x_{s}^{B}$ and therefore $x_{s}^{B}<x_{s, t}^{B}$. Thus a domestic firm will invest more under a first-best policy. Finally, recall that the tax is an increasing function of $x$ implying a lower tax to be paid under a second-best policy. 


\section{ApPendix 3: ProOF OF LeMma 1}

We can distinguish 2 situations corresponding to 2 possible relations between $\bar{x}_{C}^{B}$ and $\bar{x}_{C}^{C}$. Therefore, first we study the relationship between these two maximums.

When $k>k C=\frac{2}{\beta\left(8-8 \gamma-4 \gamma^{2}+2 \gamma^{3}+\gamma^{4}\right)}, \quad \bar{x}_{C}^{B}<\bar{x}_{C}^{C}$. However, since $\bar{x}_{C}^{B}$ and $\bar{x}_{C}^{C}$ are discontinuous in $\frac{1}{4\left(1-\gamma^{2}\right)}$ and $\frac{1}{\left(2-\gamma^{2}\right)^{2}}$ respectively, and since the first one is the biggest one, we have to asses the position of $k C$ with respect to it. Only when $\gamma<0.857, k C$ is bigger than zero; moreover, $\frac{1}{4\left(1-\gamma^{2}\right)}<\underline{k}<k C$. Yet, when $\gamma>0.857, k C$ is negative and $\bar{x}_{C}^{B}\left(\frac{1}{4\left(1-\gamma^{2}\right)}\right) \rightarrow \infty$ while $\bar{x}_{C}^{B}\left(\frac{1}{4\left(1-\gamma^{2}\right)}\right) \rightarrow$ finite value, hence $\bar{x}_{C}^{B}>\bar{x}_{C}^{C}$ for all $k>\underline{k}$.

It follows from the above discussions that

$$
\min \left\{\bar{x}_{C}^{B}, \bar{x}_{C}^{C}\right\}= \begin{cases}\bar{x}_{C}^{B} & \text { if } k>\frac{2}{\beta\left(8-8 \gamma-4 \gamma^{2}+2 \gamma^{3}+\gamma^{4}\right)} \text { and } \gamma<0.857 . \\ \bar{x}_{C}^{C} & \text { otherwise }\end{cases}
$$

2 cases regarding the behavior of $\pi_{C}^{B}$ arises from the above relation between $\bar{x}_{C}^{B}$ and $\bar{x}_{C}^{C}$.

1. When $\pi_{C}^{B}$ is a decreasing function on $\left(\bar{x}_{C}^{C}, c\right)$, then parameters $k$ and $\gamma$ are in the same range as when $\bar{x}_{C}^{B}=\min \left\{\bar{x}_{C}^{B}, \bar{x}_{C}^{C}\right\}$.

2. When $\pi_{C}^{B}$ is an increasing function on $\left(\bar{x}_{C}^{C}, \bar{x}_{C}^{B}\right)$ (more precisely on $\left.\left(0, \bar{x}_{C}^{B}\right)\right)$.

Case 1.

Since the parametrical form of $\pi_{C}^{B}\left(s^{C}\left(\bar{x}_{C}^{C}\right), \bar{x}_{C}^{C}\right)$ is very complicated we designed a $x_{\text {high }}$ such that $x_{\text {high }}=\frac{2-\gamma}{2\left[4 k \beta\left(1-\gamma^{2}\right)-1\right]}(1-c)>\bar{x}_{C}^{C}$ and $\pi_{C}^{B}\left(s^{C}\left(x_{\text {high }}\right), x_{\text {high }}\right)$ can be reduced to a less complicated value, namely $\pi_{C}^{B}\left(s^{C}\left(x_{\text {high }}\right), x_{\text {high }}\right)=\frac{k \beta\left(1-\gamma^{2}\right)\left(8-4 \gamma-2 \gamma^{2}-\gamma^{3}\right)^{2}-\gamma^{6}}{4 \beta\left(4-\gamma^{2}\right)^{2}\left(1-\gamma^{2}\right)\left[4 k \beta\left(1-\gamma^{2}\right)-1\right]}(1-c)^{2}$. If we subtract from this expression $\bar{\pi}_{B}^{B}$ we can show that in the resulting expression, the numerator is an increasing function on $k$ when $k>\frac{2}{\beta\left(8-8 \gamma-4 \gamma^{2}+2 \gamma^{3}+\gamma^{4}\right)}$. The 
denominator is positive. Since, for $k=\frac{2}{\beta\left(8-8 \gamma-4 \gamma^{2}+2 \gamma^{3}+\gamma^{4}\right)}$ the numerator is positive (equal with $\frac{f(\gamma)(1-c)^{2}}{\left(8-8 \gamma-4 \gamma^{2}+2 \gamma^{3}+\gamma^{4}\right)^{2}}$ where $f(\gamma)$ is a polynomial function of degree 18 with no root on [0,1], positive in 0), then $\bar{\pi}_{B}^{B} \leq \pi_{C}^{B}\left(s^{C}\left(x_{\text {high }}\right), x_{\text {high }}\right)<\pi_{C}^{B}\left(s^{C}\left(\bar{x}_{C}^{C}\right), \bar{x}_{C}^{C}\right)$.

\section{Case 2.}

As in case 1 , since the value of $\pi_{C}^{B}\left(s^{C}\left(\bar{x}_{C}^{C}\right), \bar{x}_{C}^{C}\right)$ looks very complicated we use instead of $\bar{x}_{C}^{C}$ a $x_{\text {low }}$ such that $x_{\text {low }}=\frac{1-\gamma}{4 k \beta\left(1-\gamma^{2}\right)-1}(1-c)<\bar{x}_{C}^{C}$. For such an investment we get $\pi_{C}^{B}\left(s^{C}\left(x_{\text {low }}\right), x_{\text {low }}\right)=\frac{4 k \beta\left(1-\gamma^{2}\right)\left(8-4 \gamma-2 \gamma^{2}-\gamma^{3}\right)^{2}-\left(4-3 \gamma^{2}\right)^{2} \gamma^{2}}{16 \beta\left(4-\gamma^{2}\right)^{2}\left(1-\gamma^{2}\right)\left[4 k \beta\left(1-\gamma^{2}\right)-1\right]}(1-c)^{2}$. If we subtract from this expression $\bar{\pi}_{B}^{B}$ we can show that in the resulting expression, the numerator is an increasing function on $k$. The denominator is positive. Since for $k=\frac{4-3 \gamma^{2}}{2 \beta(1-\gamma)(2+\gamma)\left(2-\gamma^{2}\right)^{2}}$ the numerator is positive (equal with $\frac{g(\gamma)(1-c)^{2}}{(2+\gamma)^{2}\left(2-\gamma^{2}\right)^{4}}$ where $g(\gamma)$ is a polynomial function of degree 20 with no root on $[0,1]$, positive in 0$)$, then $\bar{\pi}_{B}^{B} \leq \pi_{C}^{B}\left(s^{C}\left(x_{\text {low }}\right), x_{\text {low }}\right)<\pi_{C}^{B}\left(s^{C}\left(\bar{x}_{C}^{C}\right), \bar{x}_{C}^{C}\right)$. 


\section{APPENDIX 4}

1. Assume that the government had chosen the level s for the subsidy and that the domestic firm invested $x$ in innovation. In this case, depending on the type of competition in the market, the firm's profits are given by

$$
\begin{aligned}
& \pi_{\text {Bertrand }}^{1}(x, s)=\frac{1}{\beta\left(1-\gamma^{2}\right)\left(4-\gamma^{2}\right)^{2}}\left[\left(2-\gamma-\gamma^{2}\right)(1-c)+\left(2-\gamma^{2}\right)(x+s)\right]^{2}-k x^{2} \\
& \pi_{\text {Cournot }}^{1}(x, s)=\frac{1}{\beta\left(4-\gamma^{2}\right)^{2}}[(2-\gamma)(1-c)+2(x+s)]^{2}-k x^{2} .
\end{aligned}
$$

We can infer from the above expression that, regardless of the type of market interaction, the domestic firm's profits are increasing in the level of subsidy. It follows that, since Bertrand competition attracts an output tax and Cournot an output subsidy, $\pi_{B}^{B}<\pi_{C}^{B}$ and $\pi_{B}^{C}<\pi_{C}^{C}$.

The profits $\pi_{B}^{B}$ and $\pi_{\mathrm{C}}^{\mathrm{C}}$ are given by the formula (8) and (22) respectively, and $\pi_{C}^{B}$ and $\pi_{\mathrm{B}}^{\mathrm{C}}$ by

$$
\begin{aligned}
& \pi_{C}^{B}\left(s^{C}(x), x\right)=\frac{1}{4 \beta\left(1-\gamma^{2}\right)}\left[\left(1-\gamma \frac{4+\gamma^{2}}{8-2 \gamma^{2}}\right)(1-c)+x\right]^{2}-k x^{2} \\
& \pi_{B}^{C}\left(s^{B}(x), x\right)=\frac{1}{4 \beta}\left[\left(1-\gamma \frac{4-3 \gamma^{2}}{8-6 \gamma^{2}+\gamma^{4}}\right)(1-c)+x\right]^{2}-k x^{2} .
\end{aligned}
$$

But both above functions are increasing in $\mathrm{x}$. However, $4 \beta \sqrt{\pi_{C}^{B}\left(s^{C}(x), x\right)+k x^{2}}$ is increasing faster in $\mathrm{x}$ than $4 \beta \sqrt{\pi_{B}^{C}\left(s^{B}(x), x\right)+k x^{2}}$. Since

$$
\begin{aligned}
& \pi_{C}^{B}\left(s^{C}(0), 0\right)=\frac{(1-c)^{2}}{4 \beta\left(1-\gamma^{2}\right)}\left(1-\gamma \frac{4+\gamma^{2}}{8-2 \gamma^{2}}\right)^{2}-k x^{2}> \\
& \pi_{B}^{C}\left(s^{B}(0), 0\right)=\frac{(1-c)^{2}}{4 \beta}\left(1-\gamma \frac{4-3 \gamma^{2}}{8-6 \gamma^{2}+\gamma^{4}}\right)^{2}-k x^{2}
\end{aligned}
$$

it follows that $\pi_{B}^{C}<\pi_{C}^{B}$.

$4 \beta \sqrt{\pi_{B}^{C}\left(s^{B}(x), x\right)+k x^{2}}$ is increasing slower in $x$ than $4 \beta \sqrt{\pi_{B}^{B}\left(s^{B}(x), x\right)+k x^{2}}$. Therefore if $\pi_{B}^{B}\left(s^{B}(c), c\right)<\pi_{B}^{C}\left(s^{B}(c), c\right)$, than $\pi_{B}^{B}<\pi_{B}^{C}$. So

$$
\frac{\pi_{B}^{C}\left(s^{B}(c), c\right)-\pi_{B}^{B}\left(s^{B}(c), c\right)}{\gamma^{3}} 16 \beta\left(1-\gamma^{2}\right)\left(8-6 \gamma^{2}+\gamma^{4}\right)^{2} \text { is given by }
$$




$$
\begin{aligned}
& 128-128 \gamma-160 \gamma^{2}+176 \gamma^{3}+48 \gamma^{4}-76 \gamma^{5}+4 \gamma^{6}+11 \gamma^{7}-2 \gamma^{8}-\gamma^{9}- \\
& c^{2} \gamma\left(64-80 \gamma^{2}+24 \gamma^{4}+\gamma^{6}\right)-2 c\left(64-64 \gamma-80 \gamma^{2}+80 \gamma^{3}+24 \gamma^{4}-24 \gamma^{5}+2 \gamma^{6}-\gamma^{7}-\gamma^{8}\right)
\end{aligned}
$$

Since this is a decreasing function of $c$, and since it is still positive in the highest value that $c$ can take $\left(1-\frac{\gamma}{2-\gamma^{2}}\right)$ than $\pi_{B}^{B}\left(s^{B}(c), c\right)<\pi_{B}^{C}\left(s^{B}(c), c\right)$.

If $\gamma$ and $c$ are on the gray area in the figure, then we have $\bar{x}_{C}^{B}<\bar{x}_{C}^{C}$,

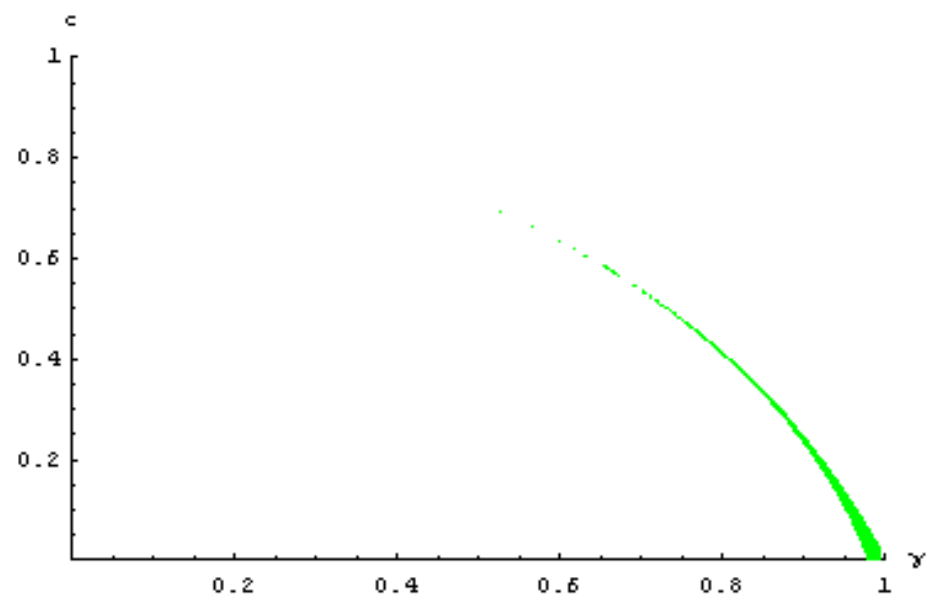

2. Since $\pi_{B}^{B}<\pi_{B}^{C}$ for all $x>0$, then $\bar{\pi}_{B}^{B}<\bar{\pi}_{B}^{C}$.

3. In order to show that $\pi_{C}^{C}<\pi_{C}^{B}$ when $\gamma>0.9783$, we consider

$$
\begin{aligned}
& \frac{\pi_{C}^{C}\left(s^{C}(x), x\right)-\pi_{C}^{B}\left(s^{C}(x), x\right)}{\gamma^{3}} 16 \beta\left(1-\gamma^{2}\right)\left(8-6 \gamma^{2}+\gamma^{4}\right)^{2} \text { that equals } e 1(x) \text { where } \\
& \begin{aligned}
e 1(x)= & (1-c)^{2}\left(128-128 \gamma-96 \gamma^{2}+80 \gamma^{3}+32 \gamma^{4}-12 \gamma^{5}-4 \gamma^{6}-\gamma^{7}\right)+ \\
& +4(1-c) x\left(32-32 \gamma-24 \gamma^{2}+16 \gamma^{3}+8 \gamma^{4}-2 \gamma^{5}-\gamma^{6}\right)-4 x^{2} \gamma\left(4-\gamma^{2}\right)^{2} .
\end{aligned}
\end{aligned}
$$

The first derivative with respect to $x$ is

$$
\frac{\partial e 1}{\partial x}(x)=4\left(4-\gamma^{2}\right)\left[(1-c)\left(8-8 \gamma-4 \gamma^{2}+2 \gamma^{3}+\gamma^{4}\right)-2 x \gamma\left(4-\gamma^{2}\right)\right]
$$

Since for $\gamma>0.857$, this derivative is negative $\left(8-8 \gamma-4 \gamma^{2}+2 \gamma^{3}+\gamma^{4}<0\right)$, the function $e 1(x)$ has its maximum in $x=0$. But

$$
e 1(0)=(1-c)^{2}\left(128-128 \gamma-96 \gamma^{2}+80 \gamma^{3}+32 \gamma^{4}-12 \gamma^{5}-4 \gamma^{6}-\gamma^{7}\right)
$$

and is negative for $\gamma>0.978\left(128-128 \gamma-96 \gamma^{2}+80 \gamma^{3}+32 \gamma^{4}-12 \gamma^{5}-4 \gamma^{6}-\gamma^{7}<0\right)$. 
4. We would like to identify the conditions under which the sufficient conditions (s2) do not hold, for any level of investment cost $k$. It is immediate that whenever $\pi_{C}^{C}<\pi_{C}^{B}$, the sufficient conditions are never verified if $\max _{x}\left\{\pi_{C}^{C}-\pi_{C}^{B}\right\}<\min _{w}\left\{\bar{\pi}_{B}^{C}<\bar{\pi}_{B}^{B}\right\}$, where $w=k \beta$.

For $\gamma>0.8576$, the first derivative of $\pi_{C}^{C}-\pi_{C}^{B}$ with respect to $x$ is always negative for $x \in$ $[0, c]$. Therefore this function reaches its maximum when there is no investment $(x=0)$, and

$$
\max _{x}\left\{\pi_{C}^{C}-\pi_{C}^{B}\right\}=(1-c)^{2} \gamma^{3} \frac{128-128 \gamma-96 \gamma^{2}+80 \gamma^{3}+32 \gamma^{4}-12 \gamma^{5}-4 \gamma^{6}-\gamma^{7}}{16\left(1-\gamma^{2}\right)\left(8-6 \gamma^{2}+\gamma^{4}\right)^{2}} \text {. }
$$

$\bar{\pi}_{B}^{C}<\bar{\pi}_{B}^{B}$ 's first derivative with respect to $w$ has a sign given by

$$
\begin{aligned}
& \operatorname{sign}\left\{-\left(2-\gamma^{2}\right)^{5}\left(4-2 \gamma^{2}-\gamma^{4}\right)+\right. \\
& +2 w\left(2-\gamma^{2}\right)^{2}\left(128-128 \gamma-160 \gamma^{2}+176 \gamma^{3}+48 \gamma^{4}-76 \gamma^{5}+4 \gamma^{6}+11 \gamma^{7}-2 \gamma^{8}-\gamma^{9}\right)-4 w^{2}(1-\gamma)^{2} \\
& \left.\left(512+256 \gamma-896 \gamma^{2}-256 \gamma^{3}+704 \gamma^{4}+96 \gamma^{5}-288 \gamma^{6}-24 \gamma^{7}+64 \gamma^{8}+12 \gamma^{9}-4 \gamma^{10}-\gamma^{11}\right)\right\} .
\end{aligned}
$$

This later function is always negative for any $w>\underline{k} \beta$. Hence, $\min _{w}\left\{\bar{\pi}_{B}^{C}<\bar{\pi}_{B}^{B}\right\}$ is reached for $w \rightarrow \infty$ and equals

$$
\min _{w}\left\{\bar{\pi}_{B}^{C}<\bar{\pi}_{B}^{B}\right\}=(1-c)^{2} \gamma^{3} \frac{128-160 \gamma^{2}+16 \gamma^{3}+64 \gamma^{4}-12 \gamma^{5}-8 \gamma^{6}+3 \gamma^{7}+\gamma^{8}}{16(1+\gamma)\left(8-6 \gamma^{2}+\gamma^{4}\right)^{2}} .
$$

Whenever $\gamma>0.9257$, the expression (b) is smaller that (c). Consequently, regardless of the level of parameters, when $\gamma>0.9257$, the sufficient conditions do not hold. 


\section{REFERENCES}

Bagwell, K. and R.W. Staiger (1994): "The Sensitivity of Strategic and Corrective R\&D Policy in Oligopolistic Industries," Journal of International Economics 36: 133-150.

Bhagwati, J. N., 1989. "Is Free Trade Passé After All?" Weltwirschaftliches Archiv, Vol. 1, 17-44

Brander, J.A. and B.J. Spencer (1985): “Export Subsidies and Market Share Rivalry,” Journal of International Economics 18: 83-100.

Brander, J.A. (1995): "Strategic Trade Policy," in G. Grossman and K. Rogoff, eds. The Handbook of International Economics Vol. 3, North-Holland, p. 1395-1455.

Carmichael, C (1987): "The Control of Export Credit Subsidies and Its Welfare Consequences," Journal of International Economics 23:1-9.

D'Aspremont and A. Jacquemin. 1988. "Cooperative and Noncooperative R\&D in Duopoly with Spillovers." American Economic Review 78: 113-37.

Eaton, J. and G. Grossman (1986): "Optimal Trade and Industrial Policy under Oligopoly," Quarterly Journal of Economics 101: 383-406.

Grossman, G.M. and G. Maggi (1998): "Free Trade versus Strategic Trade: A Peek into Pandora's Box," CEPR, Discussion Paper, No. 1784.

Gruenspecht, H.K (1988): "Export Subsidies for Differentiated Products," Journal of International Economics 24: 331-344.

Helpman and Krugman (1989): “Trade policy and market structure," Cambridge, Mass. and London: MIT Press, pages xii, 191..

Hinloopen, J. (1997): "Subsidizing R\&D-Cooperatives", Discussion paper, no 15, Centre for Industrial Economics, University of Copenhagen.

Karp, L. S. and J. M. Perloff (1995): "The Failure of Strategic Industrial Policies due to Manipulation by Firms," International Review of Economics and Finance 4(1):1-16.

Krugman, P. R. (1987): "Is Free Trade Passé?." Journal Of Economic Perspectives, No 2, 131-141.

Levy, S. and S. Nolan (1991): "Trade and Foreign Investment Policies under Imperfect Competition: Lessons for Developing Countries," Journal of Development Economics, 37(1-2): 31-62.

Maggi, G. (1996): "Strategic Trade Policies with Endogenous Mode of Competition," The American Economic Review Vol. 86 No.1: 237-258.

Maggi (1999): "Strategic Trade Policy under Incomplete Information,“ International Economic Review 40(3): 571-594.

Martin (1993): Advanced Industrial Economics, Oxford and Cambridge, Mass.: Blackwell.

Neary, J.P. (1994): “Cost Asymmetries in International Subsidy Games: Should Governments Help Winners or Losers?” Journal of International Economics 37: 197-218. 
Neary, J.P. and D. Leahy (1997): "Public Policy Towards R\&D in Oligopolistic Industries," American Economic Review 87: 642-662.

Neary, J.P. and D. Leahy (2000): "Strategic Trade and Industrial Policy towards Dynamic Oligopolies," Economic Journal 110: 484-508.

Qiu, L. (1994): "Optimal Strategic Trade Policy under Asymmetric Information," Journal of International Economics 36(3-4): 333-354.

Spencer, B.J. and J.A. Brander (1983): "International R\&D Rivalry and Industrial Strategy," Review of Economic Studies 50: 707-722.

Tirole, J. (1988): The Theory of Industrial Organization,Cambridge, MA and London: The MIT Press.

Žigić, K. (1998): "Strategic Trade Policy: How Important is the Informational Constraint? The Case of Optimal Tariff when Technological Innovations Spill Over to the Foreign Competitor," CEPR, Discussion Paper, No. 1957. 